\title{
A Large-Scale Mutational Analysis of Two-Component Signaling Systems of Lonsdalea quercina Revealed that KdpD-KdpE Regulates Bacterial Virulence Against Host Poplar Trees
}

\author{
Ruo-Lan Yang, ${ }^{1,2}$ Chao-Ying Deng, ${ }^{2}$ Jin-Wei Wei, ${ }^{2,3}$ Wei He, ${ }^{1}$ Ai-Ning Li, ${ }^{1,+}$ and Wei Qian ${ }^{2,+}$ \\ ${ }^{1}$ The College of Forestry, Beijing Forestry University, Beijing 100083, China; ${ }^{2}$ State Key Laboratory of Plant Genomics, Institute \\ of Microbiology, Chinese Academy of Sciences, Beijing 100101, China; and ${ }^{3}$ School of Biological Sciences, University of \\ Chinese Academy of Sciences, Beijing 100049, China
}

Accepted 7 February 2018.

\begin{abstract}
Poplar, which is a dominant species in plant communities distributed in the northern hemisphere, is commonly used as a model plant in forestry studies. Poplar production can be inhibited by infections caused by bacteria, including Lonsdalea quercina subsp. populi, which is a gram-negative bacterium responsible for bark canker disease. However, the molecular basis of the pathogenesis remains uncharacterized. In this study, we annotated the twocomponent signal transduction systems (TCSs) encoded by the L. quercina subsp. populi $\mathrm{N}-5-1$ genome and identified 18 putative histidine kinases and 24 response regulators. A large-scale mutational analysis revealed that 19 TCS genes regulated bacterial virulence against poplar trees. Additionally, the deletion of $k d p E$ or overexpression of $k d p D$ resulted in almost complete loss of bacterial virulence. We observed that $k d p E$ and $k d p D$ formed a bi-cistronic operon. KdpD exhibited autokinase activity and could bind to $\mathrm{KdpE}\left(K_{\mathrm{d}}=5.73 \pm 0.64 \mu \mathrm{M}\right)$. Furthermore, $\mathrm{KdpE}$ is an OmpR family response regulator. A chromatin immunoprecipitation sequencing analysis revealed that $\mathrm{KdpE}$ binds to an imperfect palindromic sequence within the promoters of 44 genes, including stress response genes Lqp0434, Lqp3037, and Lqp3270. A comprehensive analysis of TCS functions may help to characterize the regulation of poplar bark canker disease.
\end{abstract}

Trees belonging to the genus Populus are usually dominant species in plant communities distributed in the northern

Ruo-Lan Yang and Chao-Ying Deng contributed equally to this study.

The draft genomic sequence of L. quercina subsp. populi N-5-1 was deposited in the SRA database of GenBank under accession number of SRX3296076

${ }^{\dagger}$ Corresponding authors: Wei Qian; E-mail: qianw@im.ac.cn and Ai-Ning Li; E-mail: li_aining@bjfu.edu.cn

Funding: This work was supported by the Fundamental Research Funds for the Central Universities grant BLX2013015, the National Natural Science Foundation of China grants 31400545, 31600062, and 31370127, the Ministry of Science and Technology of China grant 2016YFD0100602, and the State Key Laboratory of Plant Genomics.

*The $\boldsymbol{e}$-Xtra logo stands for "electronic extra" and indicates that four supplementary figures, four supplementary tables, and one supplementary movie are published online.

@ 2018 The American Phytopathological Society hemisphere. Because they are fast-growing trees, wild Populus spp. and their hybrids have been planted over large areas for landscape greening as well as multiple industrial uses (Jansson and Douglas 2007). However, the productivity of Populus spp. is substantially decreased by infectious diseases caused by various microbial pathogens (Tuskan et al. 2006), including Lonsdalea quercina subsp. populi, which is a short rod-shaped, gram-negative bacterium and the causative agent of poplar bark canker disease (Berruete et al. 2016; Brady et al. 2012). This bacterium belongs to the family Pectobacteriaceae of the class Gammaproteobacteria ( $\mathrm{Li}$ et al. 2017) and was previously classified into the genera Brenneria or Erwinia. After entering tree stems through the epidermis, the pathogen migrates to the phloem and xylem of the poplar trunk. A successful infection by this bacterium results in the production of a large amount of sticky cream-like sap and causes the phloem to rapidly decompose, which eventually leads to plant death (Shang et al. 2015; Tóth et al. 2013). Between 2008 and 2010, frequent outbreaks of bacterial canker disease in northern China accounted for 50 to $70 \%$ of the detected poplar diseases and caused substantial losses in wood production (Li et al. 2014). However, like many other bacterial pathogens of trees, the molecular mechanism underlying L. quercina subsp. populi pathogenesis remains largely unknown (Yang et al. 2014), which impedes the development of effective approaches to control this bacterial pathogen.

In bacteria, two-component signal transduction systems (TCSs) are the dominant sense-and-respond mechanisms that regulate physiological processes and cellular behavior, including virulence (Stock et al. 2000). A typical TCS consists of a membrane-bound histidine kinase (HK), which functions as a cellular sensor, and a cytosolic response regulator (RR). After detecting a specific environmental or host stimulus via the $\mathrm{N}$-terminal signal input region, HKs autophosphorylate a conserved histidine residue (His) within their DHp (dimerization and histidine phosphotransfer) and CA (catalytic and ATP binding) domains, and then, transfer the phosphoryl group to an invariant aspartic acid residue (Asp) within the receiver domain of their cognate RR (Hoch 2000). In addition to receiver domains, RRs usually contain C-terminal effector domains, which exhibit transcription factor and enzymatic activities or are directly involved in protein-protein interactions to control downstream cellular factors (Galperin 2010). The TCS genes account for approximately 2 or $3 \%$ of the gene repertoire of a bacterial genome (Wuichet et al. 2010), and their copy numbers 
determine the adaptive potential of certain bacteria living in various ecological niches (Capra and Laub 2012). Several TCSs mediate the production of bacterial virulence factors, such as PhoP-PhoQ of Samonella enterica (Dalebroux and Miller 2014), QseC-QseB of uropathogenic Escherichia coli (Hunstad and Justice 2010), RpfC-RpfG and VgrS-VgrR of Xanthomonas campestris (Cai et al. 2017; Wang et al. 2016), and GacS-GacA of Pseudomonas aeruginosa (Brencic et al. 2009). Because of their central role in regulating the production of virulence factors, TCSs are ideal molecular targets for the development of novel antibacterial chemicals (Gotoh et al. 2010). Several groups of lead compounds have been identified, which can prevent bacterial infections by inhibiting TCS activity (Eguchi et al. 2017; Rasko et al. 2008; Worthington et al. 2013).

There have been relatively few studies that examined the biological functions of TCSs in bacterial pathogens infecting trees. In this study, we annotated the TCSs encoded by the Lonsdalea quercina subsp. populi N-5-1 genome, which carries genes for $18 \mathrm{HKs}$ and $24 \mathrm{RRs}$. To analyze the regulatory roles of these TCSs, we systematically mutated TCS-encoding genes by insertional inactivation and obtained 32 viable mutants. Phenotypic profiling revealed that inactivation of 19 genes attenuated bacterial virulence against host poplar trees. Additionally, we observed that a novel TCS (KdpD-KdpE, Lqp0376Lqp0375) not only controls bacterial virulence, growth, and swimming motility, it also regulates bacterial resistance to oxidative and chloramphenicol stresses. A chromatin immunoprecipitation sequencing (ChIP-seq) analysis used to dissect the regulon of $\mathrm{KdpE}$ revealed that this RR regulates approximately 44 genes. Moreover, $\mathrm{KdpE}$ is a transcription factor that modulates the expression of downstream genes by directly binding to an imperfect palindromic sequence acting as a cisregulatory element within promoter regions. Therefore, we analyzed the function of the TCSs of Lonsdalea quercina subsp. populi at a genome-wide scale and identified a core virulence modulator.

\section{RESULTS}

\section{Annotation of TCSs encoded}

by the Lonsdalea quercina subsp. populi genome.

By high-throughput sequencing, we obtained a draft genome of L. quercina subsp. populi N-5-1, which was isolated from poplar stems grown in Henan Province, China (Yang et al. 2014). The bacterial genome was approximately 3.8 megabases and encoded 3,000 genes (GenBank accession number SRP120272). An analysis of the putative bacterial proteome resulted in the identification of conserved domains involved in HK-RR phosphorylation and led to the annotation of $18 \mathrm{HKs}$ and 24 RRs (Fig. 1; Supplementary Table S3). Additionally, 15 pairs of HK and RR genes that were located close to each other in the genome may constitute operons encoding various TCSs (Fig. 1). However, three HK and nine RR genes were not clustered with any of the other HK and RR genes in the genome, making them 'orphan' TCS genes (Steiner et al. 2011). Compared with the other bacterial species that also belong to

Histidine kinases

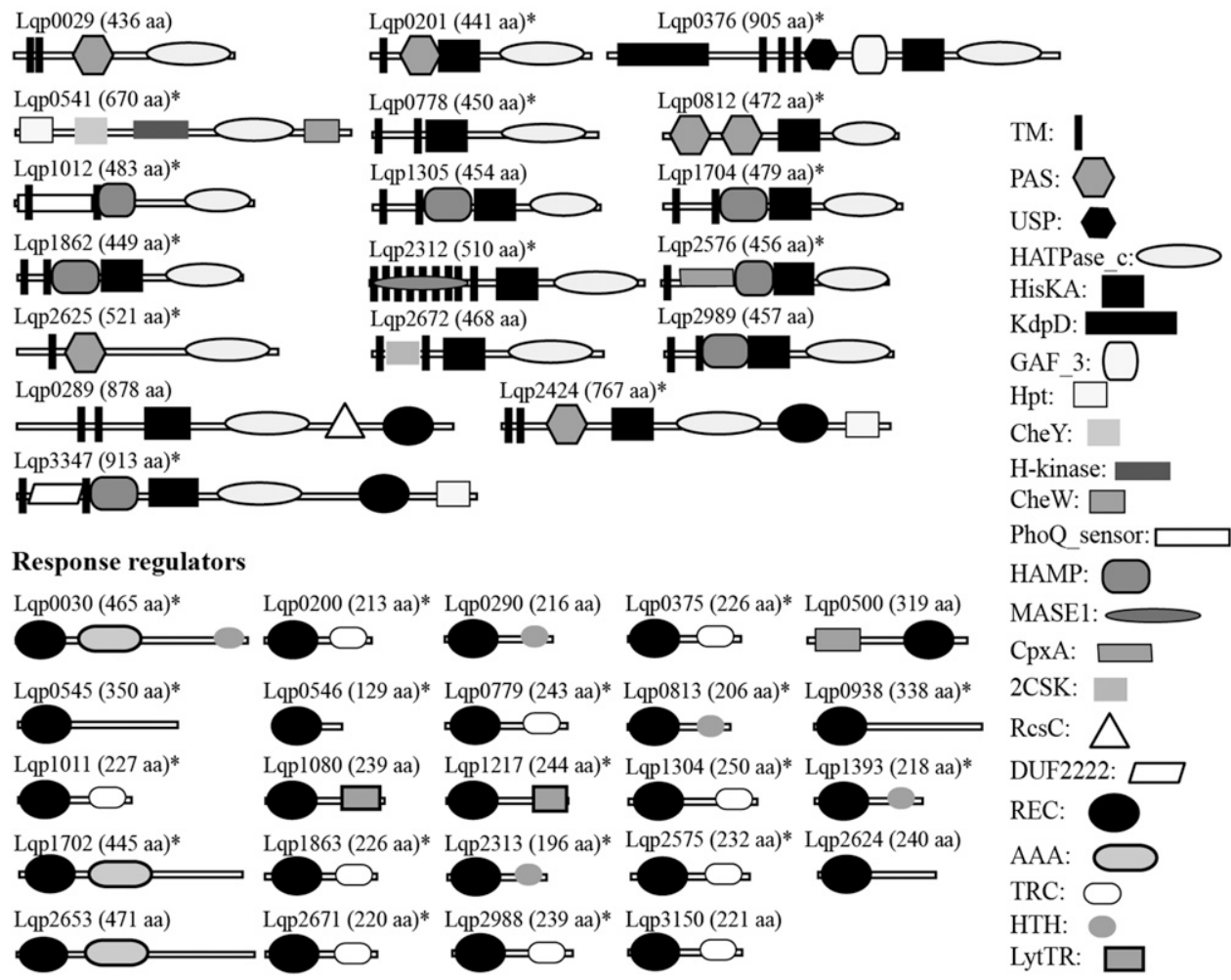

Fig. 1. Putative secondary structures of all annotated two-component signal transduction system proteins of Lonsdalea quercina subsp. populi N-5-1. Protein domains were predicted by searching the Pfam 31.0 and SMART databases (cut-off E value $\leq 1.0$ ). Domain names are the same as those in the Pfam databases: HisKA (Pfam accession number PF00512), HATPase_c (PF02518), PAS (PF00989), HAMP (PF00672), USP (PF00582), KdpD (PF02702), GAF_3 (PF13492), Hpt (PF01627), CheY (CheY-binding domain, PF09078), CheW (PF01584), PhoQ_Sensor (PF08918), MASE1 (PF05231), CpxA_peri (PF16527), 2CSK (PF08521), REC (Response regulator receiver domain, PF00072), HTH (PF01381), DFU2222 (Uncharacterized signal transduction histidine kinase domain, PF09984), AAA (PF00004), RcsC (RcsC $\alpha-\beta$-Loop domain, PF09456), TRC (Trans_reg_C domain, PF00486), Hpt (PF01627), and LytTR (LytTr DNA-binding domain, PF04397). Vertical black bars represent putative transmembrane helices at the N-terminal regions, which were predicted by TMpred. Protein lengths are indicated $(\mathrm{a} a=$ amino acid). An asterisk indicates that the coding gene is potentially located in an operon and that insertion inactivation of it may cause a polar effect. 
the Pectobacteriaceae family, the number of TCS of L. quercina subsp. populi is relatively smaller. For example, Pectobacterium spp. usually have 55 to 60 TCS proteins and Dickeya spp. encode approximately 60 to 70 TCS proteins (Ortet et al. 2015).

Among the HKs, 16 contained transmembrane (TM) helices at the N-terminal and were predicted to be inner membrane-bound proteins (Fig. 1). The remaining two (Lqp0541 and Lqp0812), which lacked a TM helix, were HKs involved in detecting intracellular stimuli in the cytosol. Besides the DHp and CA domains, additional receiver domains were detected in three HKs (Lqp0289, Lqp3347, and Lqp2424), which enabled them to function as hybrid-type HKs involved in a multistep phosphorelay (Fig. 1). Compared with the TCSs of other bacterial species, such as Xanthomonas spp. and Pseudomonas spp. (Ortet et al. 2015), the sensor domains of L. quercina subsp. populi HKs are relatively simple. Only a few sensors have been annotated, including the PAS (Per-Arnt-Sim) domain detecting redox, light, or oxygen, GAF (cGMP-specific phosphodiesterases, adenylyl cyclases, and FhlA) domain potentially involved in second messenger signaling, MASE1 (membrane-associated sensor) domain, probably detecting metal, sugar, or oxygen, and various function-unknown domains such as HAMP (present in HKs, adenyl cyclases, methyl-accepting proteins, and phosphatases) and DUF2222, indicating that the bacterial pathogen lives in a relatively stable environment.

The deduced L. quercina subsp. populi proteome contains four RRs (Lqp0545, Lqp0546, Lqp0938, and Lqp2624) that lack recognizable output domains (Fig. 1). These 'stand-alone' RRs may be directly involved in protein-protein interactions during regulatory activities (Galperin 2006). Furthermore, the L. quercina subsp. populi N-5-1 draft genome did not encode any RRs exhibiting enzymatic activities, such as those involved in the synthesis and degradation of the bacterial second messenger cyclic di-GMP (i.e., GGDEF, EAL, and HD-GYP domains) and methyltransferases (CheR and CheB domains). Most of the RRs (21 proteins) were transcription factors, because they encode C-terminal DNA-binding domains. Therefore, it seems that the L. quercina subsp. populi TCSs modulate physiological processes, mainly via transcription factor networks.

\section{Mutation of HK and RR genes} and phenotypic profiling of the mutants.

We insertionally inactivated the annotated $\mathrm{HK}$ and RR genes (by homologous recombination, single crossover method) to investigate their regulatory roles. A total of 42 recombinant suicide pWM91 vectors were constructed and used for mutagenesis by vector integration (Supplementary Fig. S1). We obtained 32 mutants (16 HK and $16 \mathrm{RR}$ mutants) that were verified by polymerase chain reaction (PCR) (Supplementary Tables S1 and S2). All mutants grew normally on the rich nutrient yeast gycerol (NYG) agar medium, except that the surface of the mutants of Lqp0200, Lqp0375, and Lqp0376 exhibited much more smooth. However, the growth of the Lqp0200 and Lqp0375 mutants were considerably arrested on the minimal medium for Xanthomonas (MMX) (Fig. 2A and B).
A

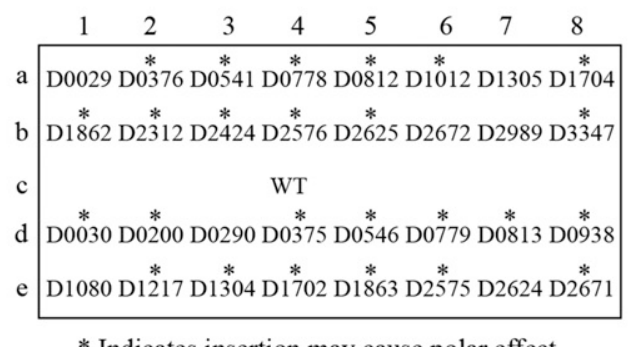

* Indicates insertion may cause polar effect
B

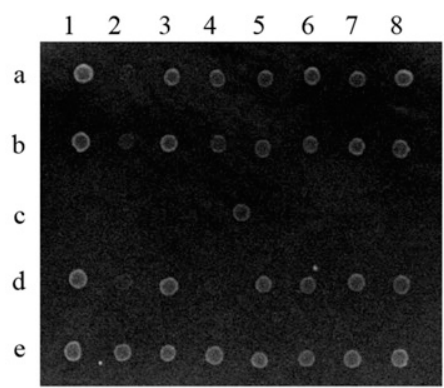

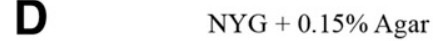

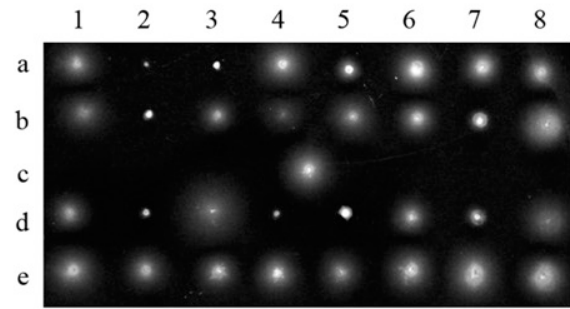

C

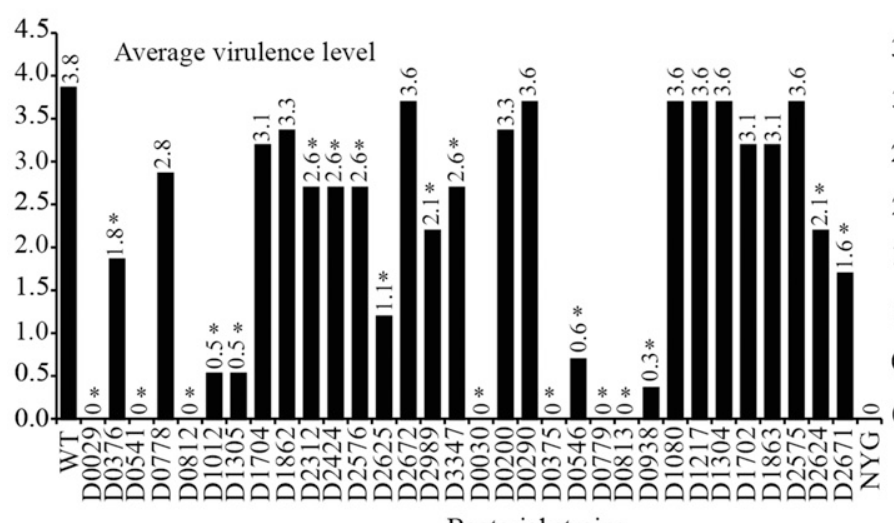

Bacterial strains
E

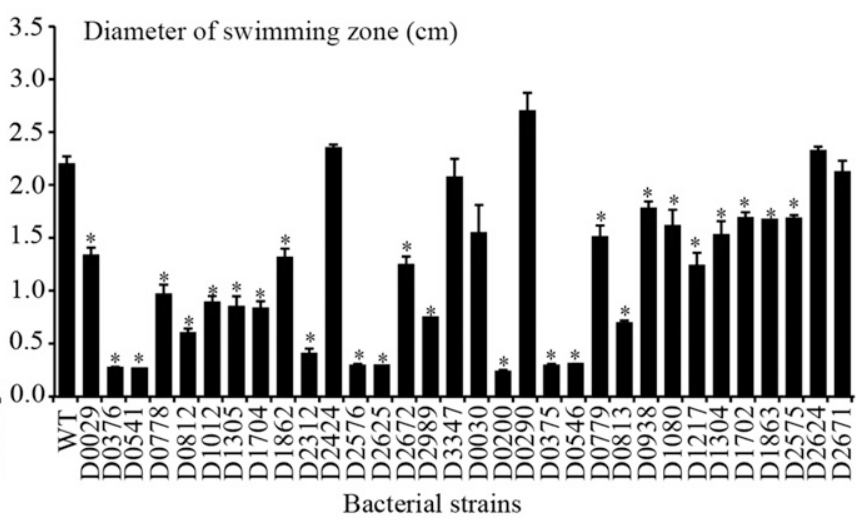

Fig. 2. Large-scale insertional inactivation of genes encoding two-component signal transduction systems of Lonsdalea quercina subsp. populi N-5-1 and phenotypic characterization of the mutants. A, Mutant positions on the plates presented in B and D. Asterisks indicate that insertion inactivation of the gene may cause a polar effect. B, Growth of bacterial strains on minimal medium for Xanthomonas (MMX). Bacterial strains were grown for 1 week at $30^{\circ} \mathrm{C}$. C, Average virulence levels of mutant strains against host poplar (Populus $\times$ canadensis). Branches were inoculated with bacterial cultures (optical density at $600 \mathrm{~nm}=0.8 \pm 0.01)$, and disease symptoms and virulence levels were evaluated 8 days after inoculation. The average scores of virulence levels were labeled on the column. An asterisk indicates significant difference compared with the wild-type strain (WT) strain, based on Student's $t$ test $(P \leq 0.05, n=3)$. D, Swimming motility of bacterial strains grown on a semisolid nutrient yeast gycerol (NYG) medium $(0.15 \%$ agar). The medium was inoculated with bacterial strains using toothpicks, and bacteria were grown for $24 \mathrm{~h}$ at $30^{\circ} \mathrm{C}$. E, Average diameters of the bacterial swimming zones shown in C. Vertical bars represent the standard deviation. Asterisk indicates significant difference compared with the WT, based on Student's $t$ test $(P \leq 0.05, n=3)$. 
Even after repeated efforts, we were unable to inactivate 10 genes (Lqp0201 [PhoR ortholog], Lqp0289 [RcsC ortholog], Lqp0500, Lqp0545, Lqp1011, Lqp1393, Lqp2313, Lqp2653, Lqp2988, and Lqp3150), possibly because the pWM91 suicide vector knocked out genes in the L. quercina subsp. populi genome at low efficiency or some of the TCS genes are essential so a mutation would be lethal, like phoP-phoQ in $X$. campestris and walR-walK in Bacillus subtilis (Dubrac et al. 2008; Peng et al. 2017).

A number of phenotypes were then characterized for these mutants, including virulence, resistance to various metal stresses, production of extracellular polysaccharides (EPS) and enzymes, and cellular motility. Six-month-old branches of susceptible Canadian poplar (Populus $\times$ canadensis Moench, a hybrid of $P$. deltoides $\times P$. nigra) were inoculated with these bacterial mutants by wounding. A virulence assay conducted 8 days after inoculation revealed that mutations to 19 genes resulted in a significant decrease in virulence (Fig. 2C). Mutants with an inactivated Lqp0029, Lqp0030, Lqp0375, Lqp0541, Lqp0779, Lqp0812, or Lqp0813 were nonvirulent. A sequence similarity search indicated that the proteins encoded by orthologous genes in other bacteria are currently being studied, including KdpE (Lqp0375), CheA (Lqp0541), CheY (Lqp0546), RstA (Lqp0779), UhpB (Lqp2312), CpxA (Lqp2516), DcuR and DcuS (Lqp2624 and Lqp2625), QseB (Lqp2671), and EnvZ (Lqp2989). In addition, the swimming motility of the 32 generated mutants were assessed. Twenty-six mutants $(81 \%)$ exhibited significantly decreased swimming motility when grown in the semisolid NYG agar medium $(0.15 \%$ agar) (Fig. $2 \mathrm{D}$ and E). Additionally, mutations in six genes (Lqp0200, Lqp0375, Lqp0376, Lqp0541, Lqp0546, and Lqp2312) resulted in a complete lack of swimming motility. Furthermore, L. quercina subsp. populi N-5-1 did not generate measurable EPS, and mutations in its TCS genes did not change the production of extracellular enzymes and resistance to tested metal stresses $\left(\mathrm{Fe}^{3+}, \mathrm{Cu}^{2+}\right.$, and $\left.\mathrm{Zn}^{2+}\right)$.

The results of our phenotypic characterization provide functional information for these TCS genes that may be relevant for future research. However, caution must be taken because of the many genetic polymorphisms that were detected among the orthologs, which will inevitably result in functional differences during bacterial evolution. In addition, since insertion inactivation usually causes polar effect to interfere with the transcription of genes in the same operon (Figs. 1 and 2A), this added the complexity to analyze the regulatory functions of these TCS genes.

\section{Mutation of $k d p D-k d p E$ decreases bacterial virulence and affects resistance to oxidative and chloramphenicol stresses.}

We selected Lqp0375 for an in-depth study because the inactivation of this RR gene significantly decreased bacterial virulence, swimming motility, and growth on MMX (Fig. 2). This gene encodes an OmpR family RR (226 amino acids), which is a putative transcription factor with a C-terminal DNAbinding domain (TRC domain) (Fig. 1). Lqp0375 is located close to Lqp0376, which encodes a membrane-bound, orthodox HK (905 amino acids). Lqp0376 contains the following three domains that function as sensors: a N-terminal KdpD domain that is putatively located in the periplasm to detect $\mathrm{K}^{+}$and other unknown environmental stimuli, a cytoplasmic GAF domain, and a universal stress protein (USP) domain located between the TM helices and the DHp-CA region. A sequence similarity search by BlastP revealed that Lqp0375-Lqp0376 is highly conserved and similar to the KdpE-KdpD TCS in bacteria belonging to genera Pectobacterium, Dickeya, Serratia, and Yersinia (identity $>75 \%$ ). Therefore, we renamed the two genes $k d p E$ ( $L q p 0375)$ and $k d p D$ (Lqp0376). To our knowledge, the regulatory roles of $k d p D-k d p E$ orthologs have not been experimentally investigated in other plant bacterial pathogens.

A reverse transcription (RT)-PCR assay was used to investigate whether $k d p D$ and $k d p E$ are organized in an operon. Primers were designed to amplify cDNA templates potentially synthesized from the transcripts of intergenic regions (Fig. 3A). We detected a reproducible amplification product corresponding to an intergenic transcript between $k d p E$ and $k d p D$, which implied these two genes formed a bi-cistronic operon (Fig. 3B). The neighboring genes, including Lqp0373, Lqp0374, and $L q p 0377$, were not included in the $k d p D-k d p E$ operon. This observation suggests that the insertional inactivation of $k d p D$ or $k d p E$ will inevitably induce a polar effect that will increase the complexity of any subsequent genetic analyses. Thus, we constructed nonpolar, in-frame deletion mutants of $k d p D$ and $k d p E(\Delta \mathrm{kdpD}$ and $\Delta \mathrm{kdpE})$, which underwent an in-depth genetic analysis.

The inoculation of Populus $\times$ canadensis tree with the $k d p D$ and $k d p E$ nonpolar mutants revealed that the deletion of $k d p E$ significantly attenuated the bacterial virulence. The severity of the typical disease symptoms, such as disease-spot depressions and white suppuration at the inoculation sites, was substantially decreased (Fig. 3C, left panel, and D). Genetic complementation by the overexpression of a full-length $k d p E$ via the broadhost vector $\mathrm{pBBR} 1 \mathrm{MCS} 2$ almost completely restored virulence to that of the wild-type (WT) strain (Fig. 3C and D). In this complementary strain, $k d p E$ is subject to the regulation of a constitutive PlacZ promoter. Although the deletion of the HK gene $k d p D$ only slightly affected bacterial virulence (Fig. 3C, middle panel, and D), we observed that overexpressing this gene in the $k d p D$ mutant genetic background or in the WT background resulted in a complete loss of virulence (Fig. 3C, middle and right panels, and D). There was a lack of disease symptoms on tree branches inoculated with the $k d p D$-overexpressing strain (Fig. 3C and D).

To further investigate the impact of $k d p D-k d p E$ mutations on bacterial physiology, we screened a series of phenotypes. The $k d p D-k d p E$ mutations did not affect most phenotypes, such as resistance to $\mathrm{Mn}^{2+}, \mathrm{Fe}^{3+}, \mathrm{Cu}^{2+}$, and $\mathrm{Co}^{2+}$ stresses, salinity stress $(3 \% \mathrm{NaCl})$, and osmotic stress (16\% sorbitol) (Supplementary Fig. S2). However, the deletion of $k d p E$ significantly enhanced bacterial resistance to oxidative stress $\left(5 \% \mathrm{H}_{2} \mathrm{O}_{2}\right)$ and chloramphenicol, whereas $k d p D$ overexpression significantly decreased the resistance to $\mathrm{H}_{2} \mathrm{O}_{2}$ and bacterial growth in the presence of chloramphenicol (Fig. 3E). Under both oxidative and chloramphenicol stresses, the deletion of $k d p D$ did not have an observable effect on bacterial adaptability. In addition, deletion of $k d p E$ and overexpression of $k d p D$ significantly decreased the swimming motility of the bacterium. Observation by wet mount, phase contrast microscopy revealed that bacterial cells of WT, $k d p E$ complementary, and $k d p D$ deletion strains moved toward multiple directions. However, the $k d p E$ deletion mutant and $k d p D$ overexpression strain exhibited obvious deficiency in swimming because their cells tended to move in one direction (Supplementary Movie). To investigate whether the deficiency is associated with flagella, transmission electron microscope was used to observe the morphology and numbers of bacterial flagella. The observation showed that L. quericina subsp. populi cell has multiple flagella. The bacterial cells of WT, $k d p E$ complementary, and $k d p D$ deletion strains dominantly developed over three flagella ( $>50 \%$ cells, $n=50$ ) (Fig. 3F and G), whereas the $k d p E$ deletion mutant and $k d p D$ overexpression strain dominantly contains one flagellum ( $>60 \%$ cells, $n=50$ ) (Fig. 3F and G). Collectively, these results suggest that the $k d p D-k d p E$ TCS genes regulate bacterial virulence, responses to oxidative and chloramphenicol stresses, 
and the development of flagella that is important to swimming motility.

To investigate the roles of conserved phosphorylation sites of $\mathrm{KdpD}$ and $\mathrm{KpdE}$ in regulation, we constructed two recombinant strains $\left(\Delta \mathrm{kdpD}-\mathrm{kdpD}^{\mathrm{H} 682 \mathrm{~A}}\right.$ and $\left.\Delta \mathrm{kdpE}-\mathrm{kdpE}^{\mathrm{D} 53 \mathrm{~A}}\right)$. The genetic codes of His ${ }^{682}$ of $k d p D$ and $A s p^{53}$ of $k d p E$ were substituted by Ala codes, and then, the point mutated genes were provided in trans into the deletion mutants of $\Delta \mathrm{kdpD}$ and $\Delta \mathrm{kdpE}$, respectively. The virulence levels, resistance to $\mathrm{H}_{2} \mathrm{O}_{2}$ and chloramphenicol stresses of $\Delta \mathrm{kdpD}-\mathrm{kdpD}^{\mathrm{H} 682 \mathrm{~A}}$ and $\Delta \mathrm{kdpE}-\mathrm{kdpE}^{\mathrm{D} 53 \mathrm{~A}}$ strains were similar to those of the WT strains (Fig. 3C to E). Since $\mathrm{KdpE}^{\mathrm{D} 33 \mathrm{~A}}$ or $\mathrm{KdpD}^{\mathrm{H} 682 \mathrm{~A}}$ substitution constitutively erased the phosphorylation of $\mathrm{KdpE}$ or $\mathrm{KdpD}$, this genetic result indicates that the phosphorylation of $\mathrm{KdpE}$ and phosphotransfer

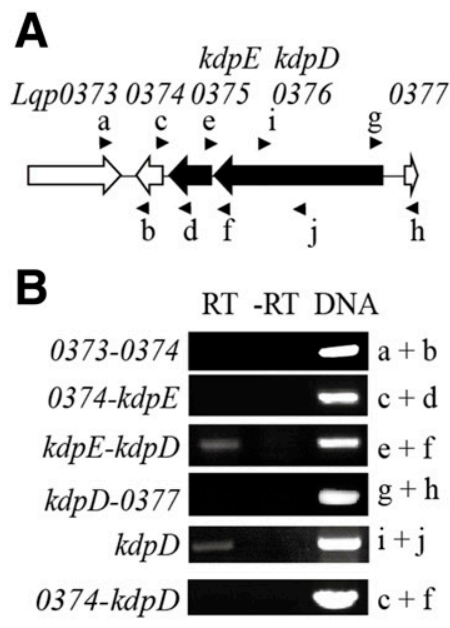

D

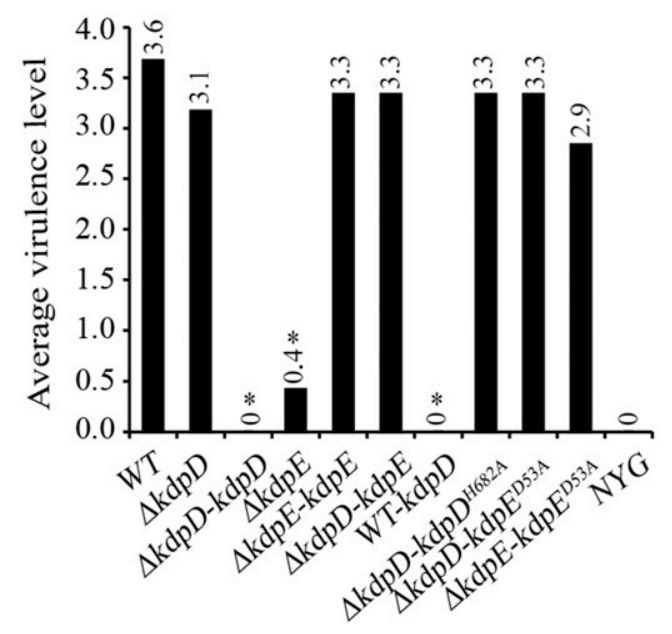

$\mathbf{F}$

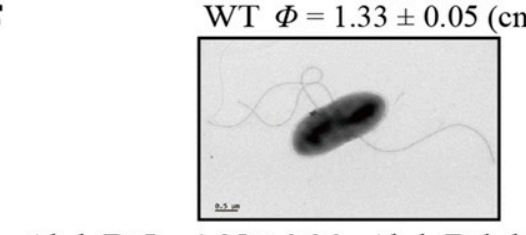

$\Delta \mathrm{kdpD} \Phi=1.35 \pm 0.06 \quad \Delta \mathrm{kdpD}-\mathrm{kdpD} \Phi=0.95 \pm 0.13$
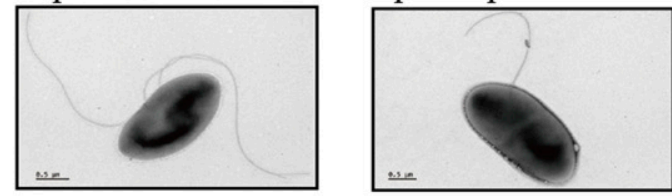

$\Delta \mathrm{kdpE} \Phi=1.11 \pm 0.05$

$\Delta \mathrm{kdpE}-\mathrm{kdpE} \Phi=1.30 \pm 0.08$
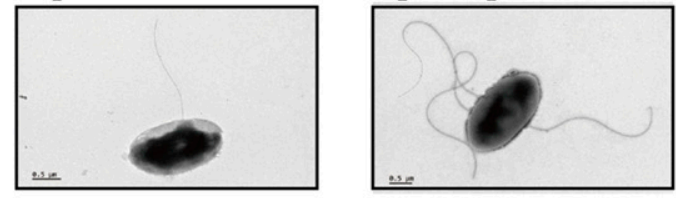
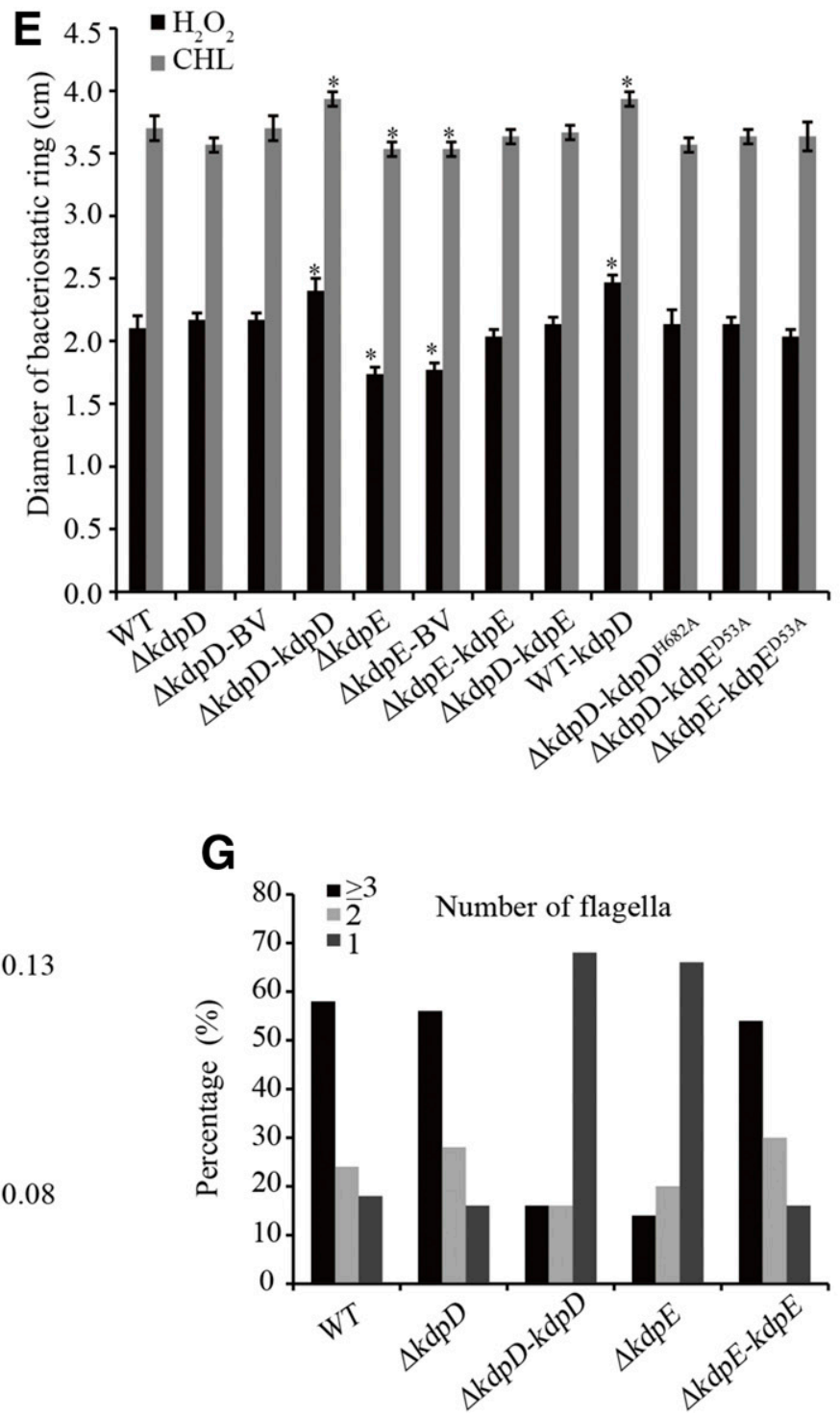
from $\mathrm{KdpD}$ to $\mathrm{KdpE}$ did not involve in regulation of these physiological processes. In addition, autophosphorylation of KdpD seems dispensable to control bacterial virulence and responses to $\mathrm{H}_{2} \mathrm{O}_{2}$ and chloramphenicol stresses.

\section{KdpD interacts with KdpE and may function as a TCS.}

To study the protein phosphorylation process of $\mathrm{KdpD}$ and $\mathrm{KdpE}$, we used E. coli BL21 (DE3) and the pET30a vector to express the full-length $k d p D$ and $k d p E$ genes. The resulting proteins were purified by affinity chromatography. Because KdpD has TM helices (Fig. 1), an inverted membrane vesicle (IMV) containing full-length KdpD was extracted and was used for an enzymatic activity assay (Fig. 4A). Meanwhile, recombinant $\mathrm{KdpE}$ and $\mathrm{KdpD}$ proteins, with substitutions in their conserved phosphorylation sites $\left(\mathrm{KdpE}^{\mathrm{D} 53 \mathrm{~A}}\right.$ and $\left.\mathrm{KdpD}^{\mathrm{H} 682 \mathrm{~A}}\right)$, were also produced and purified (Fig. 4A). An in-vitro phosphorylation assay revealed that, in the presence of $10 \mu \mathrm{Ci}$ $\left[\gamma-{ }^{32} \mathrm{P}\right] \mathrm{ATP}$, the KdpD IMV was promptly autophosphorylated within $60 \mathrm{~s}$ (Fig. 4B, lanes 1 to 3), whereas the substitution of the conserved His residue by Ala $\left(\mathrm{KdpD}^{\mathrm{H} 682 \mathrm{~A}}\right)$ resulted in a complete loss of autokinase activity (Fig. 4B, lanes 5 to 7). This result confirmed that $\mathrm{KdpD}$ is a bona fide HK. However, under the tested reaction conditions, we failed to observe the transfer of the phosphoryl group from the phosphorylated KdpD to KdpE (Supplementary Fig. S3), suggesting that unknown factors are needed for the phosphotransfer. In addition, it is not clear whether KdpD dephosphorylates $\mathrm{KdpE}$, because $\mathrm{KdpE}$ was hard to be phosphorylated using other phosphate donors, including ${ }^{32} \mathrm{P}$-labeled acetyl phosphate or heterogenous HKs (VgrS and RavS), which made the measurement of KdpD phosphatase activity technically difficult (data not shown).

To determine whether $\mathrm{KdpD}$ binds to $\mathrm{KdpE}$ in vitro, we produced and purified a truncated, soluble KdpD containing the cytosolic DHp-CA region and a maltose-binding protein (MBP) tag at the $\mathrm{C}$ terminal. A microscale thermophoresis (MST) assay revealed (Fig. 4C) the binding event between the full-length $\mathrm{KdpE}$ and the truncated $\mathrm{KdpD}$, with a relatively strong binding affinity $\left(K_{\mathrm{d}}=5.73 \pm 0.64 \mu \mathrm{M}\right)$. When the conserved phosphorylation site of $\mathrm{KdpE}$ or $\mathrm{KdpD}$ was substituted, the binding affinity between the $\mathrm{KdpE}$ and $\mathrm{KdpD}$ remarkably decreased $\left(K_{\mathrm{d}}=44.3 \pm 7.15 \mu \mathrm{M}\right.$ for $\mathrm{KdpD}-\mathrm{KdpE}^{\mathrm{D} 53 \mathrm{~A}} \mathrm{in}-$ teraction [Fig. 4D] and $K_{\mathrm{d}}=135 \pm 4.92 \mu \mathrm{M}$ for $\mathrm{KdpD}^{\mathrm{H} 682 \mathrm{~A}}$ $\mathrm{KdpE}$ interaction [Fig. 4E]), suggesting that the $\mathrm{Asp}^{53}$ residue of $\mathrm{KdpE}$ and the His ${ }^{682}$ of $\mathrm{KdpD}$ residue are critical in maintaining protein conformation and the HK-RR interaction. As negative controls, neither the MBP tag alone nor the VgrS-MBP recombinant $\mathrm{HK}$ protein (also contains a DHp-CA region) of $X$. campestris were able to bind to KdpE. Collectively, these results suggest that $\mathrm{KdpD}$ and $\mathrm{KdpE}$ may function as a TCS. The transfer of a phosphoryl group between $\mathrm{KdpD}$ and $\mathrm{KdpE}$ is complex, with additional unknown factors that may be necessary for the process in vivo.

\section{Dissection of the KdpE regulon by ChIP-seq analysis.}

The RR KdpE is an OmpR family transcription factor that contains a $\mathrm{N}$-terminal receiver domain and a $\mathrm{C}$-terminal DNAbinding domain. We used ChIP-seq to dissect the KdpE regulon and screen for genes that are directly regulated by KdpE. A bacterial strain with the $k d p E$ mutant genetic background was transformed with the pBBR1MCS2 vector carrying a genetic sequence encoding a recombinant $\mathrm{KdpE}$ with a C-terminal FLAG tag. This strain was phenotypically similar to the WT strain, indicating the FLAG tag did not affect KdpE function. This bacterial strain was cultured in NYG medium until the optical density at $600 \mathrm{~nm}\left(\mathrm{OD}_{600}\right)$ reached 0.6 , after which the bacterial cells were collected for use in a protein extraction. The DNA fragments co-immunoprecipitated with KdpE by the anti-FLAG monoclonal antibody were enriched. After the highthroughput sequencing and peak calling analysis of the ChIPseq data (Fig. 5A), 44 sites within the $5^{\prime}$ promoter regions of genes were identified (Supplementary Table S4), suggesting that KdpE directly binds to the promoters of these genes and modulates their transcription. Additionally, a consensus KdpEbinding motif was predicted, based on a MEME search involving the potential DNA binding partners (Bailey et al. 2015). The AT-rich KdpE-binding motif contained an imperfect palindromic sequence similar to TTTTAATTGGAAAA (Fig. 5B). To experimentally verify this motif, we chemically synthesized a 20-bp oligonucleotide based on the sequence of the motif (Fig. 5C). The oligonucleotides were labeled by a $5^{\prime}$-FAM (carboxyfluorescein) and were used as a DNA probe in the MST analysis. It revealed that $\mathrm{KdpE}$ protein tightly bound the oligonucleotides, with a $K_{\mathrm{d}}$ vaue of $5.55 \pm 0.242 \mu \mathrm{M}$ (Fig. 5C). When the 12 conserved nucleotides of the probe were mutated, the KdpE-DNA binding was completely eliminated (Fig. 5D). Therefore, these results identified the KdpE-binding DNA motif in L. quercina. subsp. populi.

The $44 \mathrm{KdpE}$-regulated genes were classified into 14 functional categories (Fig. 5E), including biosynthesis of macromolecules, metabolism, signal transduction, transportation, and cellular structure and division, suggesting that KdpE controls and coordinates various physiological pathways. Moreover, $\mathrm{KdpE}$ potentially regulates the expression of three other transcription factors (Lqp0677, Lqp2275, and Lqp2358). Consequently, the regulation of these downstream modulators is responsive to the environmental stimuli detected by KdpD. Additionally, the $5^{\prime}$ region of $k d p D$ was identified by ChIP-seq

\footnotetext{
Fig. 3. Mutations of Lqp0376-Lqp0375 ( $k d p D-k d p E)$ attenuated bacterial virulence and affected bacterial resistance to stresses. A and B, Operon organization of the Lqp0375-Lqp0376 ( $k d p E-k d p D$ ) two-component signal transduction system genes. A, Schematic diagram of the genomic localization of the $k d p D-k d p E$ locus. Frames with arrows indicate genes and their transcriptional directions. Gene names are listed above and the reverse transcription-polymerase chain reaction (RT-PCR) primers (a to j) are also indicated. B, Analysis of operon organization by RT-PCR. Bacterial cDNA was reverse transcribed with random primers using total RNA from Lonsdalea quercina subsp. populi N-5-1 grown overnight in nutrient yeast gycerol (NYG) medium. RT indicates PCR amplification using cDNA transcribed from RNA as templates, -RT indicates negative control (no reverse transcription during cDNA synthesis), DNA indicates positive control (total DNA used as the PCR template). Amplification of the cDNA derived from $k d p D$ mRNA was used as a positive control of RTPCR. C, Virulence assay of L. quercina subsp. populi N-5-1 strains against poplar $(P . \times$ canadensis $)$. Upper panels present the disease scabs on poplar branches inoculated with bacterial strains. Lower panels present the disease symptoms in the corresponding xylem. Poplar branches were inoculated with bacterial cultures (optical density at $600 \mathrm{~nm}=0.8 \pm 0.01$ ) and were evaluated after 8 days. D, Quantification of bacterial virulence. The average scores of virulence levels were labeled on the column. An asterisk indicates significant difference compared with the wild-type (WT) strain, based on Student's $t$ test $(P \leq 0.05, n=6)$. E, Sensitivity of $k d p E-k d p D$ in-frame deletion mutants to $\mathrm{H}_{2} \mathrm{O}_{2}$ and chloramphenicol (CHL) stresses. Filter paper disks containing $5 \mu 1$ of $5 \% \mathrm{H}_{2} \mathrm{O}_{2}$ (upper panels) or $3 \mu \mathrm{l}$ of $17 \mu \mathrm{g} / \mathrm{ml} \mathrm{CHL}$ (lower panels) were used to inhibit bacterial growth. Diameters of bacterial growth inhibition zones for $\mathrm{H}_{2} \mathrm{O}_{2}$ and CHL were measured. Vertical bars represent the standard deviation $(n=3)$. An asterisk indicates significant difference compared with the WT strain based on Student's $t$ test $(P \leq$ 0.05). F, Diameter of swimming zone and morphology of flagella of bacterial strains. Diameter of swimming zone $(\Phi)$ was listed as the average number and standard deviation $(n=6)$. The bacterial flagella were observed under transmission electron microscope. G, Distribution of the numbers of flagella in bacterial cells. For each bacterial strain, 50 cells were observed, under transmission electron microscope, to calculate the numbers of their flagella.
} 
analysis, indicating that $\mathrm{KdpE}$ autoregulates the transcription of the cognate $\mathrm{HK}$ gene $k d p D$ rather than the whole $k d p D-k d p E$ operon.

\section{KdpE directly binds to the promoter regions} of downstream genes to control their transcription.

To investigate how $\mathrm{KdpE}$ controls the expression of the downstream genes, we thoroughly investigated three genes whose promoters contain the aforementioned KdpE-binding motifs (Fig. 5B). The following three genes potentially influence virulence and oxidative stress tolerance: Lqp0434 (glycosyl transferase), Lqp3037 (bacterioferritin), and Lqp3270 (chemotaxis protein). An electrophoretic mobility shift assay (EMSA) revealed that recombinant $\mathrm{KdpE}$ can bind to the $\left[\gamma-{ }^{32} \mathrm{P}\right]$ ATP-labeled DNA probes (PLqp0434, PLqp3037, and $\mathrm{PLqp3270)}$ derived from the promoter regions of these genes to form KdpE-DNA complexes (Fig. 6A to C). When unlabeled DNA probes were added to the reaction mixtures as competitors, the isotopic signals representing KdpE-DNA complexes gradually decreased. In addition, KdpE did not bind the unrelated DNA probes from Xanthomonas campestris (Supplementary Fig. S4). These results imply that the binding of KdpE to DNA sequences of promoters is highly specific.

The Lqp0434, Lqp3037, and Lqp3270 transcript levels in different bacterial strains were quantified by quantitative realtime (q)RT-PCR). The Lqp0434, Lqp3037, and Lqp3270 transcript levels in the $k d p E$ mutant decreased 22, 38, and $42 \%$, respectively, compared with the WT strain transcript level, while the genetic complementation of $k d p E$ restored the gene expression levels to WT levels (Fig. 6D to F). To verify that the three KdpE-regulated genes contribute to the phenotypic deficiencies of the $k d p E$ mutant, we conducted epistasis analyses by separately overexpressing the Lqp0434, Lqp3037, and Lqp3270 genes in the $k d p E$ mutant genetic background via a recombinant pBBR1MCS2 vector. The $k d p E$ mutant was more resistant to oxidative stress than the WT strain (Figs. 3E and 6G and H), while the overexpression of Lqp3037 and Lqp3270 decreased the bacterial resistance levels toward that of the WT strain. In contrast, the overexpression of Lqp0434 did not significantly affect the phenotype (Fig. 6G and H). Regarding chloramphenicol stress tolerance, deleting $k d p E$ resulted in mutants that were susceptible to the antibiotic. However, the overexpression of Lqp0434, Lqp3037, and Lqp3270 restored resistance levels to approximately $90 \%$ of the WT level, which was similar to that of the genetic complementary strain. Considered together, these results indicated that $\mathrm{KdpE}$ functions as a transcription factor that binds to the promoter regions of three downstream genes to positively regulate transcription. Epistasis analyses revealed that all three genes are involved in chloramphenicol stress resistance, but Lqp0434, which encodes a glycosyl transferase, does not contribute to oxidative stress resistance.

\section{DISCUSSION}

As woody plants, poplars are model tree species for forestry studies (Jansson and Douglas 2007). Although bacterial pathogens, including L. quercina subsp. populi, can considerably decrease poplar production, the molecular regulation of the pathogenesis has not been fully characterized. In this study, we annotated putative TCS genes encoding HKs and RRs in the L. quercina subsp. populi genome. We revealed that this bacterial pathogen produces approximately 42 TCS proteins with various structures to regulate cellular homeostasis (Fig. 1). A genome-wide mutagenesis of these TCS genes indicated that 11

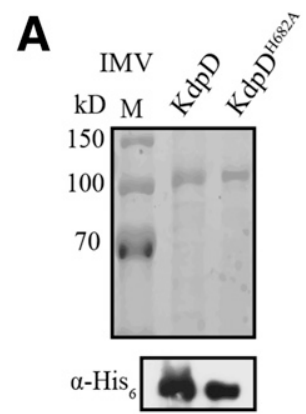

C

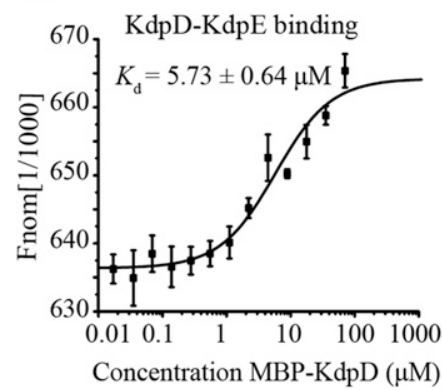

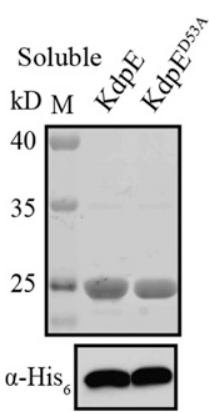

D

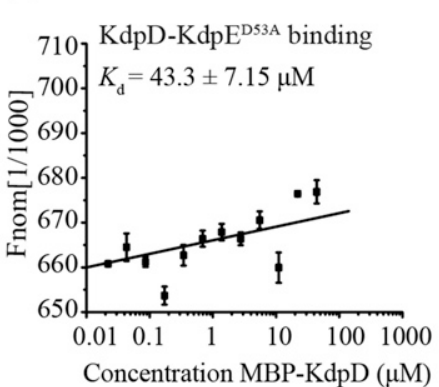

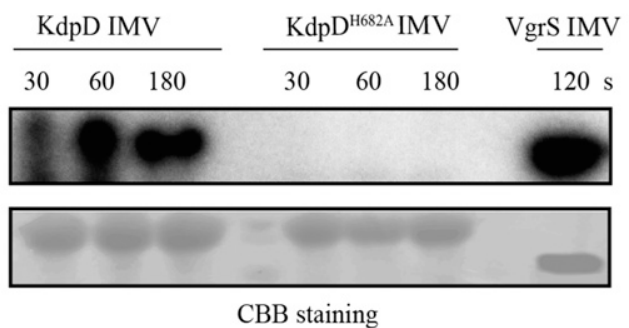

$\mathbf{E}$

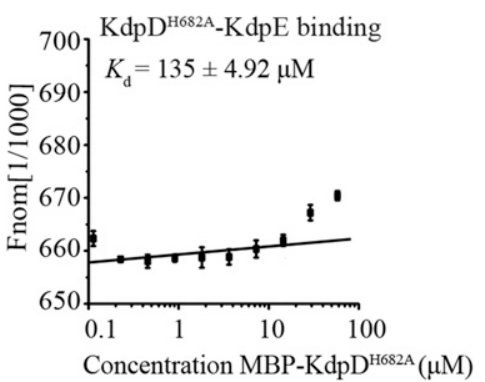

Fig. 4. KdpD-KdpE is a putative two-component signal transduction system. A, Purification of recombinant KdpE and KdpD proteins. Full-length KdpE and $\mathrm{KdpD}$ as well as their recombinant forms were expressed in Escherichia coli BL21 (DE3) cells, were purified by affinity chromatography, and were detected by Coomassie brilliant blue (CBB) staining after sodium dodecyl sulfate-polyacrylamide gel electrophoresis (SDS-PAGE). KdpD was embedded in the inverted membrane vesicles (IMV). In the lower panels, monoclonal antibody of His ${ }_{6}$ epitope tag was used to verify the recombinant proteins. B, Full-length KdpD is a histidine kinase with autokinase activity. $10 \mu \mathrm{Ci}\left[\gamma_{-}{ }^{32} \mathrm{P}\right] \mathrm{ATP}$ was co-incubated with $20 \mu \mathrm{M} \mathrm{KdpD}$ or KdpD ${ }^{\mathrm{H} 682 \mathrm{~A}} \mathrm{IMV}$ in the reaction mixture. Proteins were separated by $12 \%$ SDS-PAGE, and the isotopic signal was detected by autoradiography. C, D and E, Microscale thermophoresis (MST) assay revealed that $\mathrm{KdpD}$ directly binds to KdpE. C, KdpD-KdpE interaction. D, KdpD-KdpE ${ }^{\mathrm{D} 53 \mathrm{~A}}$ interaction. E, KdpD ${ }^{\mathrm{H} 682 \mathrm{~A}}-\mathrm{KdpE}$ interaction. Titrations of the soluble KdpD (cytosolic region) ranged from 0.01 to $1,000 \mu \mathrm{M} . K_{\mathrm{d}}=$ dissociation constant. The solid curves represent the best fit for the datapoints based on the standard KDFit function. Each binding assay was repeated three times. Black bars represent the standard deviation. 
HK genes and eight RR genes help regulate poplar canker disease development (Fig. 2). Additionally, we experimentally confirmed that KdpE physically binds to KdpD, a bona fide $\mathrm{HK}$ with autokinase activity, to form a putative TCS. KdpD-KdpE is one of the central regulators of bacterial swimming motility, growth, and responses to oxidative and antibiotic stresses (Figs. 2 and 3). Inactivation of $k d p E$ or overexpression of $k d p D$ significantly attenuated the virulence of L. quercina subsp. populi. $\mathrm{KdpE}$ is an OmpR family RR that exhibits transcription factor activity (Fig. 6). Its consensus DNA-binding motif was dissected, and a ChIP-seq analysis revealed that KdpE binds to the promoter regions of 44 genes to modulate their expression (Fig. 5), including Lqp0434, Lqp3037, and Lqp3270 (Fig. 6). To the best of our knowledge, this is the first report describing a genome-wide investigation of the regulatory mechanism of a bacterial pathogen of poplar trees.

The L. quercina genomes are approximately 3.6 to $3.8 \mathrm{Mb}$ (Ibarra Caballero et al. 2014). Our genomic annotation indicated the $L$. quercina subsp. populi N-5-1 genome encodes 42 TCS proteins (Fig. 1). The predicted secondary structures of these proteins revealed four special characteristics. i) Compared with the HKs of plant bacterial pathogens such as Pseudomonas syringae and $X$. campestris, which have relatively large genomes $(>5.0 \mathrm{Mb})$, the L. quercina subsp. populi HKs contain sensor domains with relatively simple structures (Buell et al. 2003; Qian et al. 2008a). Additionally, the L. quercina subsp. populi genome does not encode HKs with Cache, PASTA, ETR1, or HNOB domains, unlike the genomes of other bacterial species (Zhulin et al. 2003). The N-terminal input region of L. quercina subsp. populi HKs consists of PAS,
KdpD, GAF, MASE1, HAMP, and CpxA domains as sensors, implying this bacterium detects relatively few environmental stimuli during its life-cycle. ii) The number of hybrid-type HKs (with additional receiver domains) produced by L. quercina subsp. populi is much lower than that of other plant bacterial pathogens. For example, the Pseudomonas syringae genome encodes $70 \mathrm{HKs}$, including 18 hybrid-type HSKs (Ortet et al. 2015), while $X$. campestris produces $52 \mathrm{HKs}$, with 20 of them being the hybrid type (Qian et al. 2008a). In contrast, the L. quercina subsp. populi genome only encodes three hybrid-type HKs (Fig. 1). Because hybrid-type HKs are usually involved in multistep phosphorylations, their abundance reflects the ability of the bacterium to survive in diverse ecological niches (Jung et al. 2012). iii) The $L$. quercina subsp. populi N-5-1 genome does not encode RRs with output domains that are usually encoded by the genomes of other proteobacterial species, including those involved in cyclic di-GMP turnover (GGDEF, EAL, and HD-GYP domains), cyclic di-GMP binding (PilZ domain), RNA binding (ANTR domain), and transfer of methyl groups (CheB and CheR domains) (Galperin 2010). This suggests that $L$. quercina subsp. populi TCSs regulate physiological processes through a limited number of molecular mechanisms. iv) Most L. quercina subsp. populi RRs are transcription factors belonging to the OmpR, NarL, or LytR families (Fig. 1), implying the dominant mechanism by which $L$. quercina subsp. populi N-5-1 TCSs modulate cellular homeostasis involves the regulation of transcription.

We identified $\mathrm{HK}$ and RR genes affecting bacterial virulence, motility, and stress responses, based on a systematic mutational analysis (Fig. 2). The results presented herein may facilitate future studies on bacterial signaling pathways regulating these
A

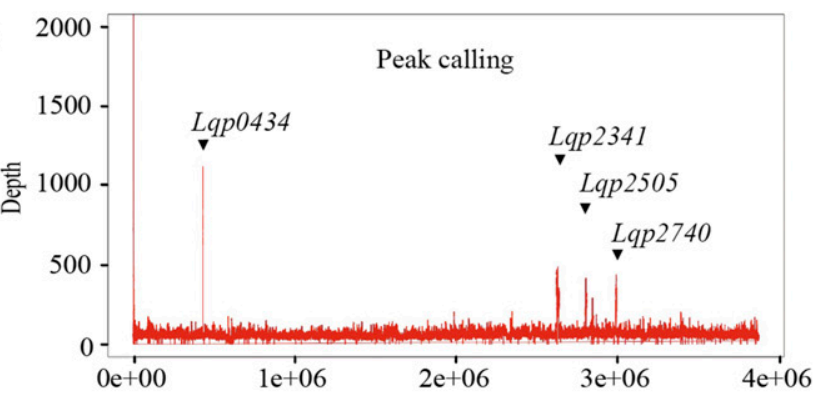

B

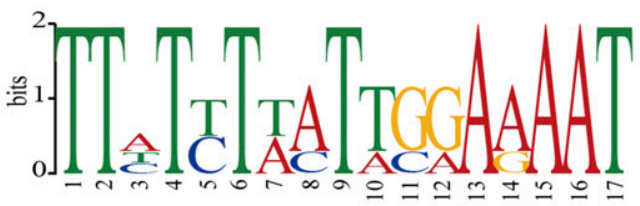

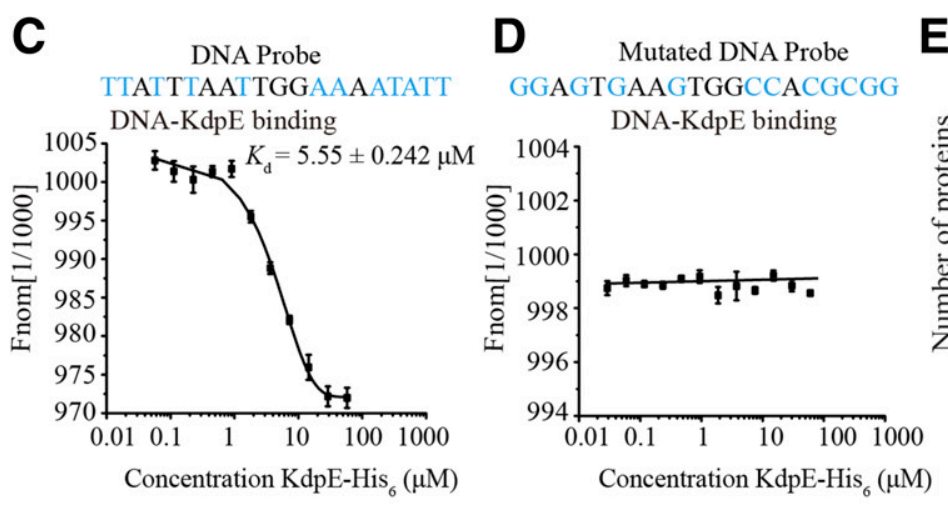

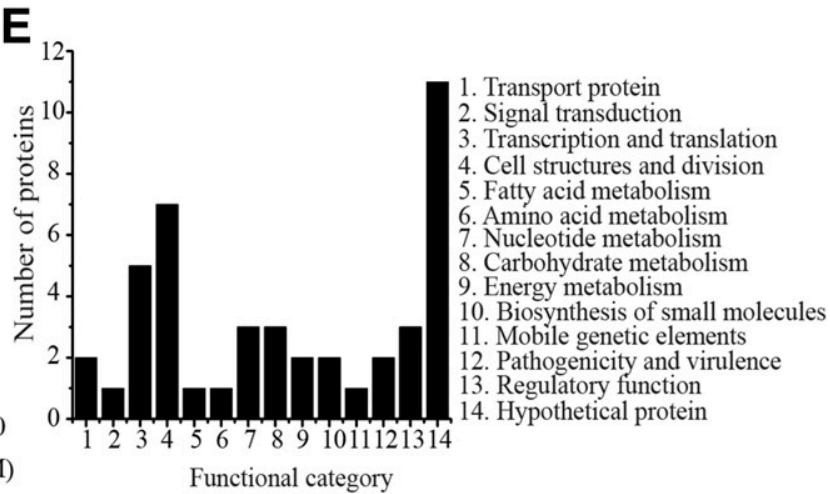

Fig. 5. Dissection of the KdpE regulon by chromatin immunoprecipitation and high-throughput sequencing (ChIP-seq). A, KdpE binding landscape in the genome of Lonsdalea quercina subsp. populi N-5-1. The KdpE ChIP-seq data were aligned to the L. quercina subsp. populi N-5-1 chromosome. B, Consensus KdpE-binding DNA motif. The binding motif was predicted by the MEME suite based on the ChIP-seq data. WebLogo was used to present the nucleotide composition. C and D, Verification of KdpE-binding DNA motif by microscale thermophoresis (MST) analysis. Two 20-bp oligonucleotides containing the predicted motif were synthesized and were labeled by $5^{\prime}$-FAM. MST analysis was used to measure the interaction between the KdpE protein and the oligonucleotide probes. C, Wild-type DNA probe. D, Mutated DNA probe. The sequences of the oligonucleotides were listed. The mutated nucleotides are shown in blue. Titrations of the KdpE ranged from 0.01 to $1,000 \mu \mathrm{M}$. $K_{\mathrm{d}}=$ dissociation constant. The solid curves represent the best fit for the datapoints, based on the standard KD-Fit function. Each binding assay was repeated three times. Black bars represent the standard deviation. E, Functional categories of the genes whose promoters putatively bind to KdpE. 
physiological processes. We observed that a TCS orthologous to KdpD-KdpE is important for controlling L. quercina subsp. populi $\mathrm{N}-5-1$ virulence as well as other physiological processes (Figs. 2 and 3), suggesting that $\mathrm{KdpD}-\mathrm{KdpE}$ is a pleiotropic TCS in this pathogen. This possibility is supported by our ChIP-seq analysis, which revealed that KdpE potentially binds to the promoters of 44 genes (Fig. 5). These downstream genes are associated with diverse functions, including virulence, stress response, nutrient assimilation, and transportation, strongly suggesting that $\mathrm{KdpD}-\mathrm{KdpE}$ is a global regulator that integrates and coordinates multiple cellular signaling pathways in L. quercina subsp. populi N-5-1. Additionally, KdpD-KdpE orthologs are widely distributed among bacteria (Freeman et al. 2013). KdpE usually comprises receiver and transcription factor domains, while KdpD contains a sensor for detecting $\mathrm{K}^{+}$, a USP domain, and a DHp-CA region responsible for

\section{A Unlabelled probe - - $\quad 500 \times 3000 \times$ $\mathrm{KdpE}$ protein $(\mu \mathrm{g}) \quad 0 \quad 5 \quad 5 \quad 10 \quad 10 \quad 10$}
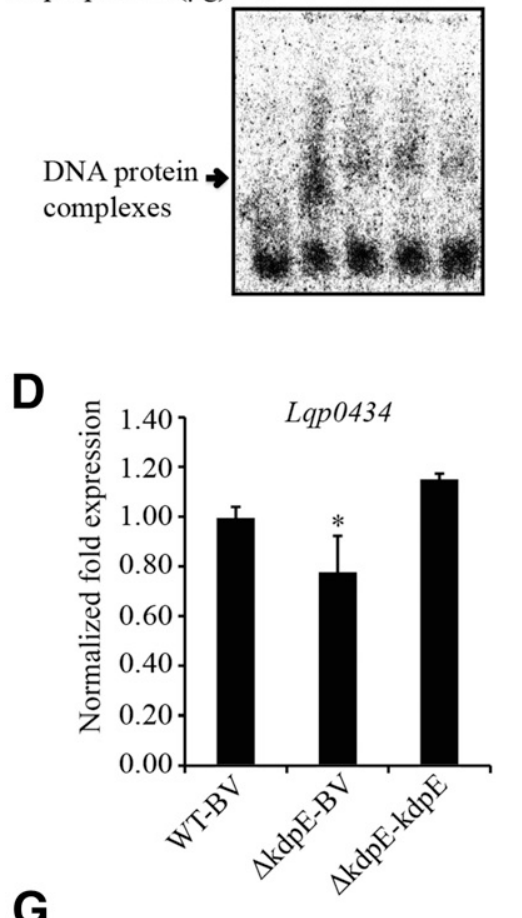

G

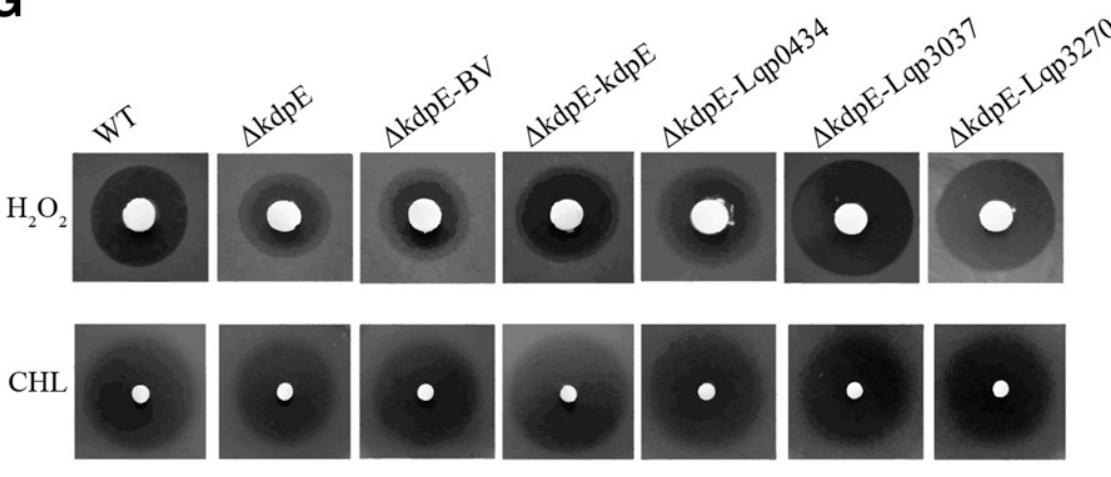

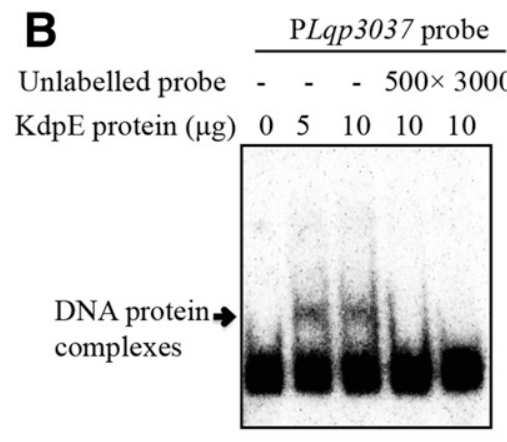

$\mathbf{E}$

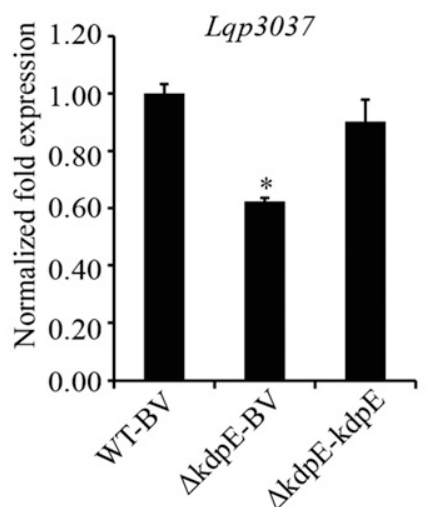

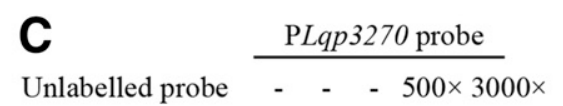

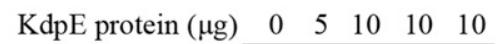

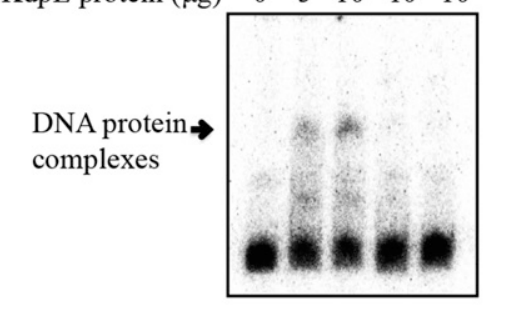

$\mathbf{F}$

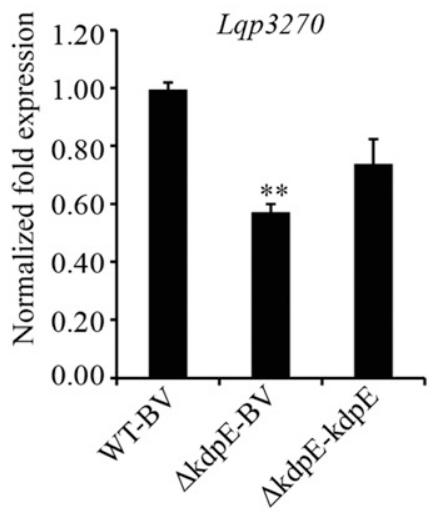

H

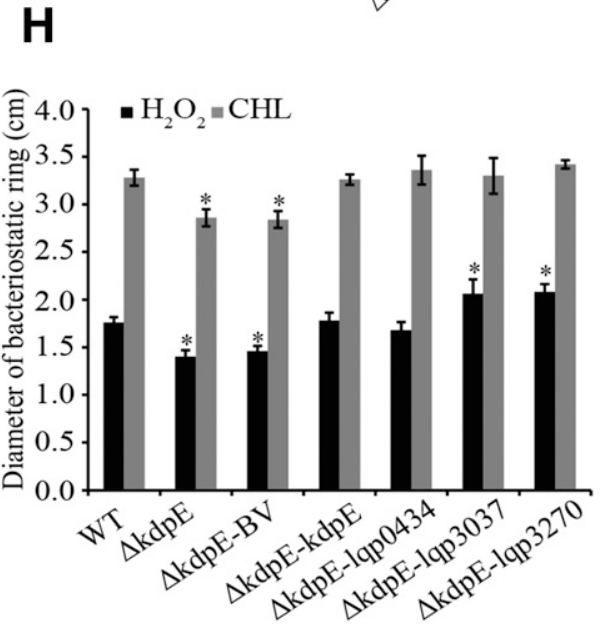

Fig. 6. KdpE is a transcription factor that regulates the expression of downstream genes by directly binding to their promoters. A, B, and $\mathbf{C}$, KdpE bound to the promoter regions of downstream genes. An electrophoretic motility shift assay (EMSA) was used to analyze the binding between KdpE and DNA probes. The polymerase chain reaction (PCR) products of the promoter regions of Lqp0434, Lqp3037, and Lqp3270 operons were labeled with [ $\left.\gamma-{ }^{32} \mathrm{P}\right] \mathrm{ATP}$ and were used as DNA probes in the EMSA (1.5 fmol in each lane). Increasing amounts of unlabeled DNA probes were used as competitors (from 500 to 3,000x). Each experiment was repeated three times. D, E, and $\mathbf{F}, k d p E$ regulates the transcription of downstream genes. Quantitative real-time reverse transcription PCR was used to quantify the Lqp0434, Lqp3037, and Lqp3270 transcript levels in different bacterial strains. The amplification of cDNA for the 16S RNA was used as an internal control. Each experiment was completed using three biological replicates. A representative result is presented in the figure. Vertical bars represent the standard deviation $(n=3)$. An asterisk represents significant difference compared with the wild-type strain (WT) strain with an empty pBBR1MCS2 vector (BV), based on Student's $t$ test $(P \leq 0.05)$. G and $\mathbf{H}$, Epistasis analysis of the regulatory relationship between $k d p E$ and the downstream genes. G, Bacterial resistance to oxidative and chloramphenicol stresses. Lqp0434, Lqp3037, and Lqp3270 were overexpressed in the kdpE mutant genetic background. Filter paper disks containing $5 \mu \mathrm{l}$ of $5 \% \mathrm{H}_{2} \mathrm{O}_{2}$ or $3 \mu \mathrm{l}$ of $17-\mu \mathrm{g} / \mathrm{ml}$ chloramphenicol (CHL) were used to inhibit bacterial growth. $\mathbf{H}$, Average diameters of growth inhibition zones for $\mathrm{H}_{2} \mathrm{O}_{2}$ and chloramphenicol. Vertical bars represent the standard deviation $(n=6)$. An asterisk indicates significant difference compared with the WT strain, based on Student's $t$ test $(P \leq 0.05)$. 
phosphorylation (Heermann and Jung 2010). This TCS has been experimentally investigated in other bacteria, which revealed that it regulates various cellular pathways (Freeman et al. 2013). For example, inactivation of $k d p E$ and $k d p D$ in animal pathogens, such as Staphylococcus aureus, Salmonella typhimurium, Yesinia pestis, and Francisella novicida, reportedly decreases bacterial virulence or survival rates in host tissues (Freeman et al. 2013; Moscoso et al. 2015; Zhao et al. 2010). However, this is not a universal principle as $k d p D-k d p E$ mutations were observed to increase Mycobacterium tuberculosis virulence (Parish et al. 2003). Additionally, this TCS does not regulate virulence in some bacterial pathogens, including X. campestris and Mycobacterium smegmatis (Ali et al. 2017; Qian et al. 2008b). Deleting the $k d p E$ or $k d p D$ orthologs in these bacteria did not considerably affect virulence against hosts. Therefore, the regulatory function of KdpD-KdpE depends on the genetic context, suggesting species-specific functions evolved during bacterial speciation. A comparison of the KdpD$\mathrm{KdpE}$ structures in L. quercina subsp. populi and in other bacteria revealed that $\mathrm{KdpE}$ is highly conserved, but there is substantial variability in the $\mathrm{KdpD}$ orthologs. The $\mathrm{KdpD}$ sensor, DHp-CA region, and USP domain are the conserved domains of KdpD proteins. However, the KdpD produced by L. quercina subsp. populi, E. coli, and $Y$. pestis includes a GAF domain between the TM region and the DHp domain, while the KdpD of Staphylococcus aureus and F. novicida lacks a GAF domain in the corresponding site. This diversity in the KdpD structure might be due to domain swapping or the accumulation of point mutations during evolution. Future studies should investigate how these species-specific domain compositions differentially regulate $\mathrm{KdpD}-\mathrm{KdpE}$ functions.

One of the more noteworthy findings of this study is that the insertional inactivation of $k d p E$ resulted in decreased bacterial virulence, whereas overexpression rather than deletion of $k d p D$ significantly attenuated bacterial virulence (Fig. 3). This observation is inconsistent with the results of previous studies on Salmonella typhimurium and Y. pestis (O'Loughlin et al. 2010; Alegado et al. 2011), in which mutations to $k d p E$ and $k d p D$ led to decreased virulence or bacterial survival in the host. Additionally, we did not observe the in-vitro transfer of a phosphoryl group from $\mathrm{KdpD}$ to $\mathrm{KdpE}$ under the tested experimental conditions. Genetic analysis demonstrated that the conserved phosphorylation sites of both $\mathrm{KdpD}$ and $\mathrm{KdpE}$ are dispensable to the regulation of virulence (Fig. 3C and D), suggesting that $\mathrm{KdpE}$ phosphorylation or the phosphotransfer from KdpD to $\mathrm{KdpE}$ is not involved in controlling virulence. However, the invitro phosphotransfer between $\mathrm{KdpD}$ and $\mathrm{KdpE}$ orthologs has been observed in E. coli and Mycobacterium tuberculosis in the presence and absence of high $\mathrm{K}^{+}$concentrations (50 to $100 \mathrm{mM}$ ) to activate KdpD (Agrawal and Saini 2014; Jung et al. 2000; Nakashima et al. 1992). The components of the reaction mixtures used in these earlier studies are similar to those used in our study. Therefore, these results suggest that the KdpD-KdpE phosphotransfer reaction in L. quercina subsp. populi is tightly controlled by the bacterium. A possible explanation for this phenomenon is that unknown cellular factors or auxiliary proteins are required. In E. coli, a subunit of the phosphoryl group chain transfer protein PtsN binds to the $\mathrm{DHp}$ domain of $\mathrm{KdpD}$, stimulates its autokinase activity, and then, enhances the KdpDKdpE phosphotransfer reaction (Mörk-Mörkenstein et al. 2017). Such auxiliary proteins have not been identified in L. quercina subsp. populi. Moreover, because HKs usually exhibit autokinase, phosphatase, and phosphotransferase activities (Goulian 2010), it is possible that KdpD mainly acts as a phosphatase to dephosphorylate the KdpE under the conditions of an in-vitro phosphorylation assay. Our efforts showed that it is technically difficult to phosphorylate $\mathrm{KdpE}$ by acetyl phosphate and noncognate $\mathrm{HKs}$, which impedes the detection of $\mathrm{KdpD}$ phosphatase activity toward KdpE-P. Whether KdpD dephoshorylates $\mathrm{KdpE}$ in L. quercina subsp. populi is an opening question. In a recent study, Schramke et al. (2016) revealed that extracellular $\mathrm{K}^{+}$inhibits the autokinase activity of $E$. coli $\mathrm{KdpD}$ but that intracellular $\mathrm{K}^{+}$stimulates the phosphatase activity of HKs. Consequently, the balance between the two enzymatic activities of $\mathrm{KdpD}$ is fine-tuned by the same ligand. Regarding the L. quercina subsp. populi KdpD-KdpE proteins, the environmental or host stimuli detected by the TCS will need to be identified, and how these stimuli modulate KdpD activities will need to be determined. Future biochemical investigations should attempt to comprehensively characterize the molecular mechanisms regulating $\mathrm{KdpD}-\mathrm{KdpE}$ functions.

\section{MATERIALS AND METHODS}

\section{Bacterial strains, plasmids, and growth conditions.}

The L. quercina subsp. populi strains were cultured in rich NYG medium (per liter, $5 \mathrm{~g}$ of tryptone, $3 \mathrm{~g}$ of yeast extract, and $20 \mathrm{~g}$ of glycerol, $\mathrm{pH} 7.0$ ) or MMX (5 g of glucose, $4 \mathrm{~g}$ of $\mathrm{K}_{2} \mathrm{HPO}_{4}, 2 \mathrm{~g}$ of $\left(\mathrm{NH}_{4}\right)_{2} \mathrm{SO}_{4}, 1 \mathrm{~g}$ of trisodium citrate, $0.2 \mathrm{~g}$ of $\mathrm{MgSO}_{4}$ ) at $30^{\circ} \mathrm{C}$, while Escherichia coli $\mathrm{DH} 5 \alpha$ cells were cultured in Luria-Bertani medium (per liter, $10 \mathrm{~g}$ of tryptone, $5 \mathrm{~g}$ of yeast extract, and $10 \mathrm{~g}$ of $\mathrm{NaCl}$ ) at $37^{\circ} \mathrm{C}$. Electrocompetent L. quercina subsp. populi cells were prepared by culturing the bacterium in 210 medium (per liter, $4 \mathrm{~g}$ of yeast extract, $8 \mathrm{~g}$ of casein enzymatic hydrolysate, $5 \mathrm{~g}$ of sucrose, $3 \mathrm{~g}$ of $\mathrm{K}_{2} \mathrm{HPO}_{4}$, and $0.3 \mathrm{~g}$ of $\mathrm{MgSO}_{4} \cdot 7 \mathrm{H}_{2} \mathrm{O}, \mathrm{pH}$ 7.0). Cells were electroporated using a Bio-Rad Pulser (Bio-Rad), under conditions of $18 \mathrm{kV} / \mathrm{cm}, 25 \mu \mathrm{F}$, and $200 \Omega$. Antibiotics were used at the following concentrations: rifampicin $(25 \mu \mathrm{g} / \mathrm{ml})$, ampicillin $(100 \mu \mathrm{g} / \mathrm{ml})$, and kanamycin $(50 \mu \mathrm{g} / \mathrm{ml})$.

\section{Genomic sequencing and gene annotation.}

For sequencing the draft genome of L. quercina subsp. populi $\mathrm{N}-5-1$, an Illumina standard shotgun library was constructed and sequenced, using the Illumina HiSeq 2000 platform, which generated $246.6 \mathrm{Mb}$ of Illumina data. The raw Illumina sequence data were filtered and assembled using Velvet and Allpaths (Zerbino and Birney 2008). Bacterial genes were identified using the Prodigal genome annotation pipeline, followed by a round of manual curation (Hyatt et al. 2010). The draft genomic sequence of $L$. quercina subsp. populi N-5-1 was deposited in the SRA database of GenBank with an accession number of SRX3296076.

\section{Construction of bacterial mutants and genetic manipulation.}

The L. quercina subsp. populi N-5-1 insertional inactivation mutants and in-frame deletion mutants were constructed by biparental conjugation using the conjugative suicide plasmid pWM91 (Metcalf et al. 1996). The L. quercina subsp. populi

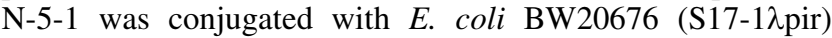
containing a recombinant pWM91 vector. Recombinant colonies with a single homologous crossover event were screened on agar-solidified NYG medium supplemented with ampicillin. In-frame deletion mutants were also constructed, using the pWM91 vector, according to a double homologous crossover method. The second crossover event was selected by culturing the bacterial strains on agar-solidified NYG medium containing $10 \%$ sucrose. Putative mutants were verified by PCR. The broadhost vector pBBR1MCS2 was used to construct genetic complementary strains (Kovach et al. 1995). The recombinant vector was subsequently and separately electrocompetented into the inframe deletion mutants of $k d p E$ or $k d p D$. The gene inserted into the pBBR1MCS2 vector was placed under the control of the $l a c Z$ promoter. The Fast Mutagenesis System (Transgene Biotech) was used to introduce point mutations. 


\section{Plant inoculation and virulence assay.}

Bacterial strains were cultured in NYG medium containing appropriate antibiotics at $30^{\circ} \mathrm{C}$ overnight, until the $\mathrm{OD}_{600}$ reached $0.8 \pm 0.01$. Branches of 6-month-old Populus $\times$ canadensis trees were wounded and were inoculated with the bacterial strains. Before inoculation, the inoculation site was washed with distilled water and was treated with absorbent cotton containing $75 \%$ alcohol. The branch surface was wounded $(1 \times 1 \mathrm{~cm}$ cross $)$ to expose the xylem and was then vaccinated with $100 \mu \mathrm{l}$ of bacterial solution. The wound was wrapped with wet cotton and cling film, after which the branches were placed in a bucket and were cultivated in an incubator set at $30^{\circ} \mathrm{C}$ with $90 \%$ relative humidity. The cotton and cling film were removed after 3 to 5 days. Disease symptoms and virulence levels were scored 8 days after inoculation. Virulence levels were estimated, as previously described, using the following standards: level $0=$ no disease symptoms; level 1 = recognizable canker and hollow depression but no purulence, lesion length $<1.0 \mathrm{~cm}$; level $2=$ recognizable canker and hollow depression, observable white purulence, lesion length $<2.0 \mathrm{~cm}$; level $3=$ large canker and hollow depression, obvious opal purulence, lesion length $<3.0 \mathrm{~cm}$; and level 4 = large canker and hollow depression, obvious brown purulence, lesion length $<5.0 \mathrm{~cm}$.

\section{Phenotypic characterization of bacterial mutants.}

The colony morphologies of the bacterial strains cultured on agar-solidified NYG medium for $24 \mathrm{~h}$ or on agar-solidified MMX for 1 week at $30^{\circ} \mathrm{C}$ were analyzed. To assess swimming motility, semisolid NYG medium $(0.15 \%$ agar $)$ was inoculated with the bacterial strains, using a toothpick. The diameter of the resulting growth zones was measured after $24 \mathrm{~h}$. For the $\mathrm{H}_{2} \mathrm{O}_{2}$ and chloramphenicol sensitivity assays, bacterial strains were cultured overnight at $30^{\circ} \mathrm{C}$ in $\mathrm{NYG}$ medium, were diluted to $\mathrm{OD}_{600}=0.4$, were mixed with melted NYG medium containing agar, and were poured into a plate just before the agar solidified. Filter paper disks $(\Phi=0.6 \mathrm{~mm})$ were placed on the medium and were then moistened with $5 \mu \mathrm{l}$ of $5 \% \mathrm{H}_{2} \mathrm{O}_{2}$ or $3 \mu \mathrm{l}$ of $17-\mathrm{mg} / \mathrm{ml}$ chloramphenicol. The diameter of the resulting growth inhibition zones was measured after $48 \mathrm{~h}$.

To directly observe the bacterial swimming, wet mount microscopy was performed directly by observing overnight bacterial cultures $\left(\mathrm{OD}_{600}\right.$ was $\left.0.4 \pm 0.01\right)$. A phase contrast microscope (Olympus DP80) was used to detect the bacterial swimming motility, which was recorded. The bacterial flagella were observed under a transmission electron microscopy (JEM-1400).

\section{RNA extraction, RT-PCR, and qRT-PCR analysis.}

Total RNA extracted from bacteria using TRIzol (Invitrogen) was treated with DNA-free DNase (Life Technologies) to remove any contaminating DNA. cDNA was synthesized using random primers (Promega) and Superscript III reverse transcription (Invitrogen). The negative control lacked reverse transcription to determine if there was any contaminating DNA, while the positive control included DNA from the WT bacterial strain. The qRT-PCR assay was conducted using Maxima SYBR green (Fermentas) and the CFX96 real-time PCR detection system (Bio-Rad). The cDNA prepared from transfermessenger RNA served as the qRT-PCR loading control.

\section{Protein expression and purification \\ for the in-vitro phosphorylation assay.}

The C-terminal $\mathrm{His}_{6}$-tagged proteins were expressed using the pET30a vector (Novagen) and E. coli BL21 (DE3) cells. The pMal-p2X vector (NEB) was used to express the truncated KdpD (MBP-G0376) protein. The methods used to express genes, purify recombinant proteins, and extract IMVs with fulllength HKs were based on the procedures described in previous studies (Cai et al. 2017; Wang et al. 2014). Briefly, His 6 -tagged, recombinant proteins were expressed and were purified using affinity chromatography with Ni-NTA agarose beads (Novagen), according to manufacturer's instructions. Purified proteins were concentrated using Centricon YM-10 columns (Millipore) and the elute buffer was changed into storage buffer for further use (50 mM Tris- $\mathrm{HCl}, \mathrm{pH}$ 8.0, $0.5 \mathrm{mM}$ EDTA, $50 \mathrm{mM} \mathrm{NaCl}$, and $5 \%$ glycerol). To prepare the inverted membrane vesicles of $\mathrm{KdpD}$, E. coli cells were broken by sonication, and the membrane containing full-length $\mathrm{HKs}$ was collected by ultracentrifugation with $200,000 \times g, 60 \mathrm{~min}$ at $4^{\circ} \mathrm{C}$. The membrane was washed in high-salt buffer $(20 \mathrm{mM}$ sodium phosphate, $\mathrm{pH}$ 7.0, $2 \mathrm{M} \mathrm{KCl}, 10 \%$ glycerol, $5 \mathrm{mM}$ EDTA, $5 \mathrm{mM}$ dithiothreitol [DTT], $1 \mathrm{mM}$ phenylmethylsulfonyl fluoride) and was resuspended in $0.5 \mathrm{ml}$ of storage buffer $(20 \mathrm{mM}$ Tris- $\mathrm{HCl}, \mathrm{pH} 7.5$, $10 \%$ glycerol) before use.

In vitro autokinase and phosphotransfer assays were conducted as previously described (Wang et al. 2016). Briefly, KdpD IMVs were incubated with $100 \mu \mathrm{M}$ ATP containing $10 \mu \mathrm{Ci}\left[\gamma_{-}{ }^{32} \mathrm{P}\right] \mathrm{ATP}$ (PerkinElmer) in a $20-\mu \mathrm{l}$ reaction buffer $(50 \mathrm{mM}$ Tris- $\mathrm{HCl}, \mathrm{pH} 7.8,25 \mathrm{mM} \mathrm{NaCl}, 25 \mathrm{mM} \mathrm{KCl}$, and $5 \mathrm{mM} \mathrm{MgCl}_{2}$ ) for 20 to $60 \mathrm{~s}$ at $30^{\circ} \mathrm{C}$. To analyze the phosphotransferase activity of $\mathrm{KdpD}$ toward $\mathrm{KdpE}, \mathrm{KdpD}$ was autophosphorylated as described above. Purified KdpE $(20 \mu \mathrm{M})$ was added to the reaction mixture, which was then incubated at $30^{\circ} \mathrm{C}$ for an indicated period. The reaction was stopped by the addition of $6 \times$ sodium dodecyl sulfate (SDS) loading buffer. The phosphorylated proteins were separated by $12 \%$ SDS-polyacrylamide gel electrophoresis (PAGE) and a phosphor screen was used for autoradiographic imaging. The Typhoon FLA7000 PhosphorImage system (Amersham Biosciences) was used to scan the screen. Gels were stained with Coomassie brilliant blue to visualize proteins and estimate size and abundance.

\section{ChIP.}

We used our previously described ChIP protocol (Wang et al. 2014, 2016). Briefly, bacterial strains were grown in NYG medium until the $\mathrm{OD}_{600}$ reached 0.6 to 0.7 . The cells were crosslinked with $1 \%$ formaldehyde and were subsequently quenched with $0.5 \mathrm{M}$ glycine. Bacterial cells were collected and sonicated using a Diagenode Bioruptor (Diagenode) to generate DNA fragments (150 to $300 \mathrm{bp}$ ). For the ChIP assays, $50 \mu \mathrm{l}$ of protein A sepharose (50\% slurry) and $1.5 \mu \mathrm{l}$ of antiFlag antibody were added to an $800-\mu l$ aliquot of the DNA sample and the mixture was slowly rotated at $4{ }^{\circ} \mathrm{C}$ overnight. The beads were collected by centrifugation and were washed twice with IP buffer and, then, once each with wash buffer (10 mM Tris- $\mathrm{HCl}, \mathrm{pH} 8.0,250 \mathrm{mM} \mathrm{LiCl}, 1 \mathrm{mM}$ EDTA, $0.5 \%$ Nonidet-P40, and $0.5 \%$ sodium deoxycholate), high-salt wash buffer (50 mM HEPES, pH 7.9, 500 mM NaCl, 1 mM EDTA, pH 8.0, 0.1\% SDS, $1 \%$ Triton $\mathrm{X}-100$, and $0.1 \%$ deoxycholate), and TE buffer (10 mM Tris-HCl, pH 8.0, and $1 \mathrm{mM}$ EDTA, $\mathrm{pH}$ 8.0). The immunoprecipitated chromatin was removed from the beads by adding $100 \mu \mathrm{l}$ of elution buffer $(50 \mathrm{mM}$ Tris- $\mathrm{HCl}, \mathrm{pH}$ 7.5, $10 \mathrm{mM}$ EDTA, and 1\% SDS) and the resulting solution was incubated at $65^{\circ} \mathrm{C}$ for $10 \mathrm{~min}$. The DNA was purified using a PCR purification kit (Qiagen) after an overnight reverse crosslinking step at $65^{\circ} \mathrm{C}$. High-throughput sequencing was completed using the HiSeq 2000 sequencing system (Illumina) at the Beijing Institute of Genomics.

\section{EMSA.}

The PCR products were labeled with $\left[\gamma^{32}{ }^{32} \mathrm{P}\right] \mathrm{ATP}$ using T4 polynucleotide kinase (NEB). The proteins $(10 \mu \mathrm{g})$ and probes $(1.5 \mathrm{fmol})$ were incubated in a $20-\mu \mathrm{l}$ solution consisting of reaction buffer $(10 \mathrm{mM}$ Tris- $\mathrm{HCl}, \mathrm{pH} 7.0,50 \mathrm{mM} \mathrm{KCl}, 1 \mathrm{mM}$ 
DTT, $2.5 \%$ glycerol, $5 \mathrm{mM} \mathrm{MgCl}_{2}, 50 \mathrm{ng}$ of poly[dI/dC] per microliter, and $10 \mathrm{mM}$ EDTA) at $4^{\circ} \mathrm{C}$ for $1 \mathrm{~h}$. The reaction was stopped by the addition of $60 \%$ glycerol, after which the samples were separated in a $6 \%$ native PAGE gel. The electrophoretic separation was completed at $120 \mathrm{~V}$ for about $50 \mathrm{~min}$ using $0.5 \times$ Tris-borate-EDTA buffer. Phosphorimaging screens were used to detect radioactive signals.

\section{Microscale thermophoresis measurements.}

The KdpE and KdpD binding affinities were calculated based on MST measurements. Protein labeling kit RED-NHS (Nano Temper Technologies GMBH) was used to label $10 \mu \mathrm{M}$ purified $\mathrm{KdpE}$ protein. The labeled protein was added to phosphatebuffered saline containing $0.02 \%$ Tween-20. Binding reactions were measured using Monolith NT.115 standard treated capillaries and the MST instrument (Nano Temper Technologies GMBH). The KdpD protein was serially diluted from 70 to $0.01 \mu \mathrm{M}$ to analyze the KdpD-KdpE interaction. The dissociation constant was calculated using the NanoTemper program (version 1.5.41).

\section{ACKNOWLEDGMENTS}

We thank all members in our lab for helpful comments.

\section{LITERATURE CITED}

Agrawal, R., and Saini, D. K. 2014. Rv1027c-Rv1028c encode functional KdpDE two-Component system in Mycobacterium tuberculosis. Biochem. Biophys. Res. Commun. 446:1172-1178.

Alegado, R. A., Chin, C. Y., Monack, D. M., and Tan, M. W. 2011. The twocomponent sensor kinase $\mathrm{KdpD}$ is required for Salmonella typhimurium colonization of Caenorhabditis elegans and survival in macrophages. Cell. Microbiol. 13:1618-1637.

Ali, M. K., Li, X., Tang, Q., Liu, X., Chen, F., Xiao, J., Ali, M., Chou, S. H., and He, J. 2017. Regulation of inducible potassium transporter $\mathrm{KdpFABC}$ by the KdpD/KdpE two-component system in Mycobacterium smegmatis. Front. Microbiol. 8:570.

Bailey, T. L., Johnson, J., Grant, C. E., and Noble, W. S. 2015. The MEME suite. Nucleic Acids Res. 43:W39-W49.

Berruete, I. M., Cambra, M. A., Collados, R., Monterde, A., Lopez, M. M., Cubero, J., and Palacio-Bielsa, A. 2016. First report of bark canker disease of poplar caused by Lonsdalea quercina subp. populi in Spain. Plant Dis. 100:2159.

Brady, C. L., Cleenwerck, I., Denman, S., Venter, S. N., RodríguezPalenzuela, P., Coutinho, T. A., and De Vos, P. 2012. Proposal to reclassify Brenneria quercina (Hildebrand and Schroth 1967) Hauben et al. 1999 into a new genus, Lonsdalea gen. nov., as Lonsdalea quercina comb. nov., descriptions of Lonsdalea quercina subsp. quercina comb. nov., Lonsdalea quercina subsp. iberica subsp. nov. and Lonsdalea quercina subsp. britannica subsp. nov., emendation of the description of the genus Brenneria, reclassification of Dickeya dieffenbachiae as Dickeya dadantii subsp. dieffenbachiae comb. nov., and emendation of the description of Dickeya dadantii. Int. J. Syst. Evol. Microbiol. 62: 1592-1602.

Brencic, A., McFarland, K. A., McManus, H. R., Castang, S., Mogno, I., Dove, S. L., and Lory, S. 2009. The GacS/GacA signal transduction system of Pseudomonas aeruginosa acts exclusively through its control over the transcription of the RsmY and RsmZ regulatory small RNAs. Mol. Microbiol. 73:434-445.

Buell, C. R., Joardar, V., Lindeberg, M., Selengut, J., Paulsen, I. T., Gwinn, M. L., Dodson, R. J., Deboy, R. T., Durkin, A. S., Kolonay, J. F., Madupu, R., Daugherty, S., Brinkac, L., Beanan, M. J., Haft, D. H., Nelson, W. C., Davidsen, T., Zafar, N., Zhou, L., Liu, J., Yuan, Q., Khouri, H., Fedorova, N., Tran, B., Russell, D., Berry, K., Utterback, T., Van Aken, S. E., Feldblyum, T. V., D’Ascenzo, M., Deng, W. L., Ramos, A. R., Alfano, J. R., Cartinhour, S., Chatterjee, A. K., Delaney, T. P., Lazarowitz, S. G., Martin, G. B., Schneider, D. J., Tang, X., Bender, C. L., White, O., Fraser, C. M., and Collmer, A. 2003. The complete genome sequence of the Arabidopsis and tomato pathogen Pseudomonas syringae pv. tomato DC3000. Proc. Natl. Acad. Sci. U.S.A. 100:10181-10186.

Cai, Z., Yuan, Z. H., Zhang, H., Pan, Y., Wu, Y., Tian, X. Q., Wang, F. F., Wang, L., and Qian, W. 2017. Fatty acid DSF binds and allosterically activates histidine kinase RpfC of phytopathogenic bacterium Xanthomonas campestris pv. campestris to regulate quorum-sensing and virulence. PLoS Pathog. 13:e1006304.

Capra, E. J., and Laub, M. T. 2012. Evolution of two-component signal transduction systems. Annu. Rev. Microbiol. 66:325-347.

Dalebroux, Z. D., and Miller, S. I. 2014. Salmonellae PhoPQ regulation of the outer membrane to resist innate immunity. Curr. Opin. Microbiol. 17: 106-113.

Dubrac, S., Bisicchia, P., Devine, K. M., and Msadek, T. 2008. A matter of life and death: Cell wall homeostasis and the WalKR (YycGF) essential signal transduction pathway. Mol. Microbiol. 70:1307-1322.

Eguchi, Y., Okajima, T., Tochio, N., Inukai, Y., Shimizu, R., Ueda, S., Shinya, S., Kigawa, T., Fukamizo, T., Igarashi, M., and Utsumi, R. 2017 Angucycline antibiotic waldiomycin recognizes common structural motif conserved in bacterial histidine kinases. J. Antibiot. (Tokyo) 70 251-258.

Freeman, Z. N., Dorus, S., and Waterfield, N. R. 2013. The KdpD/KdpE two-component system: Integrating $\mathrm{K}^{+}$homeostasis and virulence. PLoS Pathog. 9:e1003201.

Galperin, M. Y. 2006. Structural classification of bacterial response regulators: Diversity of output domains and domain combinations. J. Bacteriol. 188:4169-4182.

Galperin, M. Y. 2010. Diversity of structure and function of response regulator output domains. Curr. Opin. Microbiol. 13:150-159.

Gotoh, Y., Eguchi, Y., Watanabe, T., Okamoto, S., Doi, A., and Utsumi, R. 2010. Two-component signal transduction as potential drug targets in pathogenic bacteria. Curr. Opin. Microbiol. 13:232-239.

Goulian, M. 2010. Two-component signaling circuit structure and properties. Curr. Opin. Microbiol. 13:184-189.

Heermann, R., and Jung, K. 2010. The complexity of the 'simple' twocomponent system $\mathrm{KdpD} / \mathrm{KdpE}$ in Escherichia coli. FEMS Microbiol Lett. 304:97-106.

Hoch, J. A. 2000. Two-component and phosphorelay signal transduction. Curr. Opin. Microbiol. 3:165-170.

Hunstad, D. A., and Justice, S. S. 2010. Intracellular lifestyles and immune evasion strategies of uropathogenic Escherichia coli. Annu. Rev. Microbiol. 64:203-221.

Hyatt, D., Chen, G. L., Locascio, P. F., Land, M. L., Larimer, F. W., and Hauser, L. J. 2010. Prodigal: Prokaryotic gene recognition and translation initiation site identification. BMC Bioinformatics 11:119.

Ibarra Caballero, J., Zerillo, M. M., Snelling, J., Cranshaw, W., Boucher, C., and Tisserat, N. 2014. Genome sequences of strain ATCC 29281 and pin and northern red oak isolates of Lonsdalea quercina subsp. quercina. Genome Announc. 2:e0584-14.

Jansson, S., and Douglas, C. J. 2007. Populus: A model system for plant biology. Annu. Rev. Plant Biol. 58:435-458.

Jung, K., Fried, L., Behr, S., and Heermann, R. 2012. Histidine kinases and response regulators in networks. Curr. Opin. Microbiol. 15:118-124.

Jung, K., Veen, M., and Altendorf, K. 2000. K ${ }^{+}$and ionic strength directly influence the autophosphorylation activity of the putative turgor sensor KdpD of Escherichia coli. J. Biol. Chem. 275:40142-40147.

Kovach, M. E., Elzer, P. H., Hill, D. S., Robertson, G. T., Farris, M. A., Roop, R. M., 2nd, and Peterson, K. M. 1995. Four new derivatives of the broad-host-range cloning vector $\mathrm{pBBR} 1 \mathrm{MCS}$, carrying different antibioticresistance cassettes. Gene 166:175-176.

Li, Y., He, W., Ren, F. J., Guo, L. M., Chang, J. P., Cleenwerck, I., Ma, Y. C., and Wang, H. M. 2014. A canker disease of Populus $\times$ euramericana in China caused by Lonsdalea quercina subsp. populi. Plant Dis. 98: 368-378.

Li, Y., Xue, H., Guo, L. M., Koltay, A., Palacio-Bielsa, A., Chang, J., Xie, S., and Yang, X. 2017. Elevation of three subspecies of Lonsdalea quercina to species level: Lonsdalea britannica sp. nov., Lonsdalea iberica sp. nov. and Lonsdalea populi sp. nov. Int. J. Syst. Evol. Microbiol. 67:4680-4684.

Metcalf, W. W., Jiang, W., Daniels, L. L., Kim, S. K., Haldimann, A., and Wanner, B. L. 1996. Conditionally replicative and conjugative plasmids carrying lacZ $\alpha$ for cloning, mutagenesis, and allele replacement in bacteria. Plasmid 35:1-13.

Mörk-Mörkenstein, M., Heermann, R., Göpel, Y., Jung, K., and Görke, B 2017. Non-canonical activation of histidine kinase KdpD by phosphotransferase protein PtsN through interaction with the transmitter domain. Mol. Microbiol. 106:54-73.

Moscoso, J. A., Schramke, H., Zhang, Y., Tosi, T., Dehbi, A., Jung, K., and Gründling, A. 2015. Binding of cyclic di-AMP to the Staphylococcus aureus sensor kinase KdpD occurs via the universal stress protein domain and downregulates the expression of the Kdp potassium transporter. J. Bacteriol. 198:98-110.

Nakashima, K., Sugiura, A., Momoi, H., and Mizuno, T. 1992. Phosphotransfer signal transduction between two regulatory factors 
involved in the osmoregulated kdp operon in Escherichia coli. Mol. Microbiol. 6:1777-1784.

O’Loughlin, J. L., Spinner, J. L., Minnich, S. A., and Kobayashi, S. D. 2010. Yersinia pestis two-component gene regulatory systems promote survival in human neutrophils. Infect. Immun. 78:773-782.

Ortet, P., Whitworth, D. E., Santaella, C., Achouak, W., and Barakat, M. 2015. P2CS: Updates of the prokaryotic two-component systems database. Nucleic Acids Res. 43 (D1):D536-D541.

Parish, T., Smith, D. A., Kendall, S., Casali, N., Bancroft, G. J., and Stoker, N. G. 2003. Deletion of two-component regulatory systems increases the virulence of Mycobacterium tuberculosis. Infect. Immun. 71:1134-1140.

Peng, B. Y., Pan, Y., Li, R. J., Wei, J. W., Liang, F., Wang, L., Wang, F. F., and Qian, W. 2017. An essential regulatory system originating from polygenic transcriptional rewiring of PhoP-PhoQ of Xanthomonas campestris. Genetics 206:2207-2223.

Qian, W., Han, Z. J., and He, C. 2008a. Two-component signal transduction systems of Xanthomonas spp.: A lesson from genomics. Mol. PlantMicrobe Interact 21:151-161.

Qian, W., Han, Z. J., Tao, J., and He, C. 2008b. Genome-scale mutagenesis and phenotypic characterization of two-component signal transduction systems in Xanthomonas campestris pv. campestris ATCC 33913. Mol. Plant-Microbe Interact 21:1128-1138.

Rasko, D. A., Moreira, C. G., Li, R., Reading, N. C., Ritchie, J. M., Waldor, M. K., Williams, N., Taussig, R., Wei, S., Roth, M., Hughes, D. T., Huntley, J. F., Fina, M. W., Falck, J. R., and Sperandio, V. 2008. Targeting QseC signaling and virulence for antibiotic development. Science 321:1078-1080.

Schramke, H., Tostevin, F., Heermann, R., Gerland, U., and Jung, K. 2016. A dual-sensing receptor confers robust cellular homeostasis. Cell Reports 16:213-221.

Shang, J., Liu, B. L., and He, W. 2015. A new method to detect Lonsdalea quercina in infected plant tissues by real-time PCR. For. Pathol. 45: 28-35.

Steiner, E., Dago, A. E., Young, D. I., Heap, J. T., Minton, N. P., Hoch, J. A., and Young, M. 2011. Multiple orphan histidine kinases interact directly with Spo0A to control the initiation of endospore formation in Clostridium acetobutylicum. Mol. Microbiol. 80:641-654.

Stock, A. M., Robinson, V. L., and Goudreau, P. N. 2000. Two-component signal transduction. Annu. Rev. Biochem. 69:183-215.

Tóth, T., Lakatos, T., and Koltay, A. 2013. Lonsdalea quercina subsp. populi subsp. nov., isolated from bark canker of poplar trees. Int. J. Syst. Evol. Microbiol. 63:2309-2313.

Tuskan, G. A., Difazio, S., Jansson, S., Bohlmann, J., Grigoriev, I., Hellsten, U., Putnam, N., Ralph, S., Rombauts, S., Salamov, A., Schein, J., Sterck, L., Aerts, A., Bhalerao, R. R., Bhalerao, R. P., Blaudez, D., Boerjan, W., Brun, A., Brunner, A., Busov, V., Campbell, M., Carlson, J., Chalot, M.,
Chapman, J., Chen, G. L., Cooper, D., Coutinho, P. M., Couturier, J., Covert, S., Cronk, Q., Cunningham, R., Davis, J., Degroeve, S., Déjardin, A., Depamphilis, C., Detter, J., Dirks, B., Dubchak, I., Duplessis, S., Ehlting, J., Ellis, B., Gendler, K., Goodstein, D., Gribskov, M., Grimwood, J., Groover, A., Gunter, L., Hamberger, B., Heinze, B., Helariutta, Y., Henrissat, B., Holligan, D., Holt, R., Huang, W., IslamFaridi, N., Jones, S., Jones-Rhoades, M., Jorgensen, R., Joshi, C., Kangasjärvi, J., Karlsson, J., Kelleher, C., Kirkpatrick, R., Kirst, M., Kohler, A., Kalluri, U., Larimer, F., Leebens-Mack, J., Leplé, J. C., Locascio, P., Lou, Y., Lucas, S., Martin, F., Montanini, B., Napoli, C., Nelson, D. R., Nelson, C., Nieminen, K., Nilsson, O., Pereda, V., Peter, G., Philippe, R., Pilate, G., Poliakov, A., Razumovskaya, J., Richardson, P., Rinaldi, C., Ritland, K., Rouzé, P., Ryaboy, D., Schmutz, J., Schrader, J., Segerman, B., Shin, H., Siddiqui, A., Sterky, F., Terry, A., Tsai, C. J., Uberbacher, E., Unneberg, P., Vahala, J., Wall, K., Wessler, S., Yang, G., Yin, T., Douglas, C., Marra, M., Sandberg, G., Van de Peer, Y., and Rokhsar, D. 2006. The genome of black cottonwood, Populus trichocarpa (Torr. \& Gray). Science 313:1596-1604.

Wang, F. F., Deng, C. Y., Cai, Z., Wang, T., Wang, L., Wang, X. Z., Chen, X. Y., Fang, R. X., and Qian, W. 2014. A three-component signalling system fine-tunes expression kinetics of HPPK responsible for folate synthesis by positive feedback loop during stress response of Xanthomonas campestris. Environ. Microbiol. 16:2126-2144.

Wang, L., Pan, Y., Yuan, Z. H., Zhang, H., Peng, B. Y., Wang, F. F., and Qian, W. 2016. Two-component signaling system VgrRS directly senses extracytoplasmic and intracellular iron to control bacterial adaptation under iron depleted stress. PLoS Pathog. 12:e1006133.

Worthington, R. J., Blackledge, M. S., and Melander, C. 2013. Smallmolecule inhibition of bacterial two-component systems to combat antibiotic resistance and virulence. Future Med. Chem. 5:1265-1284.

Wuichet, K., Cantwell, B. J., and Zhulin, I. B. 2010. Evolution and phyletic distribution of two-component signal transduction systems. Curr. Opin. Microbiol. 13:219-225.

Yang, L., Xu, B., He, W., and Zhang, L. 2014. The HrpW protein of Lonsdalea quercina N-5-1 has pectate lyase activity and is required for full bacterial virulence. J. Basic Microbiol. 54:1126-1135.

Zerbino, D. R., and Birney, E. 2008. Velvet: Algorithms for de novo short read assembly using de Bruijn graphs. Genome Res. 18:821-829.

Zhao, L., Xue, T., Shang, F., Sun, H., and Sun, B. 2010. Staphylococcus aureus AI-2 quorum sensing associates with the KdpDE two-component system to regulate capsular polysaccharide synthesis and virulence. Infect. Immun. 78:3506-3515.

Zhulin, I. B., Nikolskaya, A. N., and Galperin, M. Y. 2003. Common extracellular sensory domains in transmembrane receptors for diverse signal transduction pathways in bacteria and archaea. J. Bacteriol. 185: 285-294. 